\title{
Internalization of Fluoride in Hydroxyapatite
} Nanoparticles

Daniel S. Mosiman ${ }^{\dagger}$, Andre Sutrisno ${ }^{\S}$, Riqiang Fu ${ }^{\ddagger}$, and Benito J. Mariñas ${ }^{*+}$

* Corresponding author

† Safe Global Water Institute, Department of Civil and Environmental Engineering, University of Illinois at Urbana-Champaign (UIUC), Urbana, Illinois 61801, United States

$\S$ NMR/EPR Laboratory, School of Chemical Sciences, University of Illinois at Urbana-Champaign (UIUC), Urbana, Illinois 61801, United States

‡ National High Magnetic Field Laboratory, Tallahassee, FL 32310, United States 
Number of Pages: 52, including references (pp. 47-52)

\section{Content Summary}

The SI contains 4 sections and includes 3 tables, 22 figures, and 6 schema.

Section S1. HAP production, page S4

Section S2. Batch tests, solute measurements, and solubility, pages S5-S9

Figures

Figure S1. $F^{-}$uptake with different influent concentrations, page S6

Figure S2. Solute concentrations, page S7

Figure S3. Ion activity products and saturation indices, page S9

\section{Schema}

Scheme S1. DCBR reactor setup, page S5

Section S3. HAP characterization, pages S10-S35

Tables

Table S1. Untreated HAP composition, page S13

Table S2. ${ }^{19} \mathrm{~F}$ NMR peak quantitation, page S24

Table S3. ${ }^{1} \mathrm{H}$ NMR peak quantitation, page S31

\section{Figures}

Figure S4. X-ray diffractograms and unit cell values, page S16

Figure S5. ATR-FTIR spectra, page S17

Figure S6. Thermogravimetric analysis, page S18

Figure S7. $\mathrm{N}_{2}$ sorption isotherm and $\mathrm{BJH}$ pore size distribution, page S19

Figure S8. BET SSAs of HAP with(out) treatment, page S19

Figure S9. ${ }^{13} \mathrm{C}$ NMR of untreated HAP, page S24

Figure S10. ${ }^{19} \mathrm{~F}$ NMR spectrum and deconvolution of 10 min fluoridated HAP, page $S 25$

Figure S11. ${ }^{19} \mathrm{~F}-{ }^{13} \mathrm{C}$ HETCOR NMR of $864 \mathrm{~h}$ fluoridated HAP, page S25

Figure S12. ${ }^{19} \mathrm{~F}$ NMR spectra and deconvolutions of fluoridated HAP heated to 50 and $300^{\circ} \mathrm{C}$, page S26

Figure S13. ${ }^{19} \mathrm{~F}$ NMR spectra of $864 \mathrm{~h}$ fluoridated HAP at 15 and $40 \mathrm{kHz}$ spin speeds, page S27

Figure S14. Transverse relaxation decay of $\mathrm{F}^{-}{ }_{\mathrm{AP}}$ resonance, page S27

Figure S15. ${ }^{1} \mathrm{H}^{19}{ }^{19} \mathrm{HETCOR}$ NMR of $864 \mathrm{~h}$ fluoridated HAP, page S28

Figure S16. Sample rotor configuration for ${ }^{1} \mathrm{H}$ DP NMR experiments, page $S 29$ 
Figure S17. ${ }^{1} \mathrm{H}$ DP NMR spectra of HAP and deconvolutions, page S30

Figure S18. ${ }^{1} \mathrm{H}$ DP NMR spectra of HAP fluoridated at 6.8 and $16 \mathrm{mg}-\mathrm{F} / \mathrm{L}$, page S32

Figure S19. ${ }^{1} \mathrm{H}$ DP NMR spectra of untreated HAP and HAP standard, page S32

Figure S20. TEM images of HAP NPs, page S34

Figure S21. PSDs of various HAP samples, page S35

Section S4. Methodology to calculate SSA, adsorption, and total F sites, pages S36-S45

\section{Figures}

Figure S22. Probability and cumulative distributions used for HAP particle model ACP layer thickness, page S39

\section{Schema}

Scheme S2. HAP/FAP unit cell, page S36

Scheme S3. HAP NP abstraction from a TEM image, page $\$ 40$

Scheme S4. HAP NP dimension analysis, page S41

Scheme S5. HAP NP surface site quantification analysis, page S42

Scheme S6. HAP NP dimensional analysis for ellipsoidal habit, page S46 


\section{SECTION S1. HAP PRODUCTION}

\section{Synthesis}

In brief, $30 \mathrm{~kg}$ of industrial grade calcium hydroxide is mixed into $1000 \mathrm{~L}$ of fluoride free rainwater collected onsite at the Nakuru Defluoridation Company (Nakuru, Kenya). The mixing vessel was kept in between $22-28^{\circ} \mathrm{C}$ and exposed to the ambient air. This slurry was mixed for several minutes to dissolve the calcium hydroxide, leading to a $\mathrm{pH} 12$. During this period, $\mathrm{CO}_{2}$ is being rapidly absorbed into the solution from the ambient air, which is where we assume the carbonate impurity originates from. Industrial grade phosphoric acid (85\%) is slowly dosed into the slurry until a $\mathrm{Ca} / \mathrm{P}$ ratio of 1.67 is reached, while addition of $\mathrm{KOH}$ ensures the $\mathrm{pH}$ remains at 10. The suspension is mixed for $2 \mathrm{~h}$, allowing for precipitation of HAP NPs, followed by dewatering and extrusion of the green body into $2 \mathrm{~mm}$ diameter cylindrical pellets, then airdried in the sun for several days. For this reason, we assume that the drying temperature reached no more than $35-40{ }^{\circ} \mathrm{C}$. 


\section{SECTION S2. BATCH TESTS, SOLUTE MEASUREMENTS, AND SOLUBILITY}

The three different sets of differential column batch reactor (DCBR, scheme S1) tests to measure $\mathrm{F}^{-}$uptake were conducted at different intervals as follows. Circle: $10 \mathrm{~min}, 40 \mathrm{~min}, 4 \mathrm{~h}$, 24 h, 144 h, 864 h. Square: 24 min, 1 h 24 min, 2 h 48 min, 16 h, 90 h, 264 h, 408 h, 576 h, 859 h. Triangle: $15 \mathrm{~min}, 1 \mathrm{~h}, 2 \mathrm{~h}, 6 \mathrm{~h}, 46 \mathrm{~h}, 72 \mathrm{~h}$. Different intervals were used to gather a more comprehensive set of data points. DCBR tests were also conducted for different initial fluoride concentrations of $6.8,8.0,12$, and $16 \mathrm{mg} / \mathrm{L}$ (figure S1).

Scheme S1. Depiction of differential column batch reactor experimental setup. Around $20 \mathrm{~mL}$ of water (or $2 \%$ of the reservoir volume) is circulated through the tubing at any one time at 60 $\mathrm{mL} / \mathrm{min}$. Contact time with the pellets lasts $\sim 1 \mathrm{~s}$. The reservoir is constantly mixed with a magnetic stirrer. Samples are taken from the reservoir.

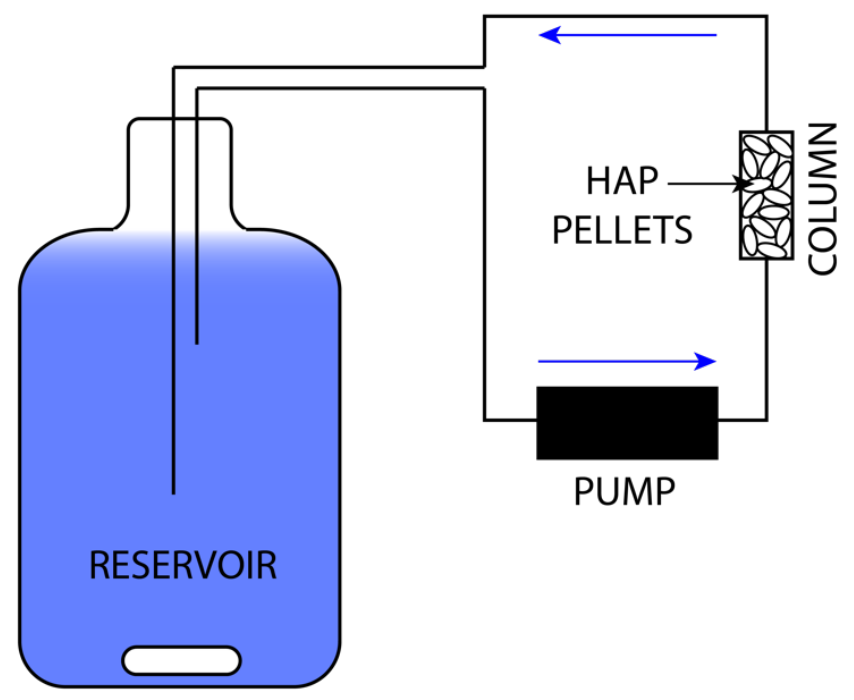

Measurement of other solutes (i.e. free calcium, total phosphate, and pH; figure S2) were carried out in separate DCBR experiments from the batch tests depicted in figure 1 of the main text, albeit with the same experimental conditions. In some batch tests all solutes including $\mathrm{F}^{-}$ were measured from the same samples in order to determine ion activity products and saturation indices of different calcium phosphate and other calcium solids (figure S3). To be 
able to measure all solutes in a sample, aliquots of $25 \mathrm{~mL}$ were taken. In those tests, fewer samples were taken so that $<15 \%$ of the final solution volume was removed. The $\mathrm{F}^{-}$uptake measurements from these experiments with influent $\mathrm{F}^{-}$concentration of $30 \mathrm{mg} / \mathrm{L}$ match the data in figure 1 of the main text. In other batch tests, samples of $11 \mathrm{~mL}$ were drawn to measure calcium and phosphate at more intervals to observe their behavior.

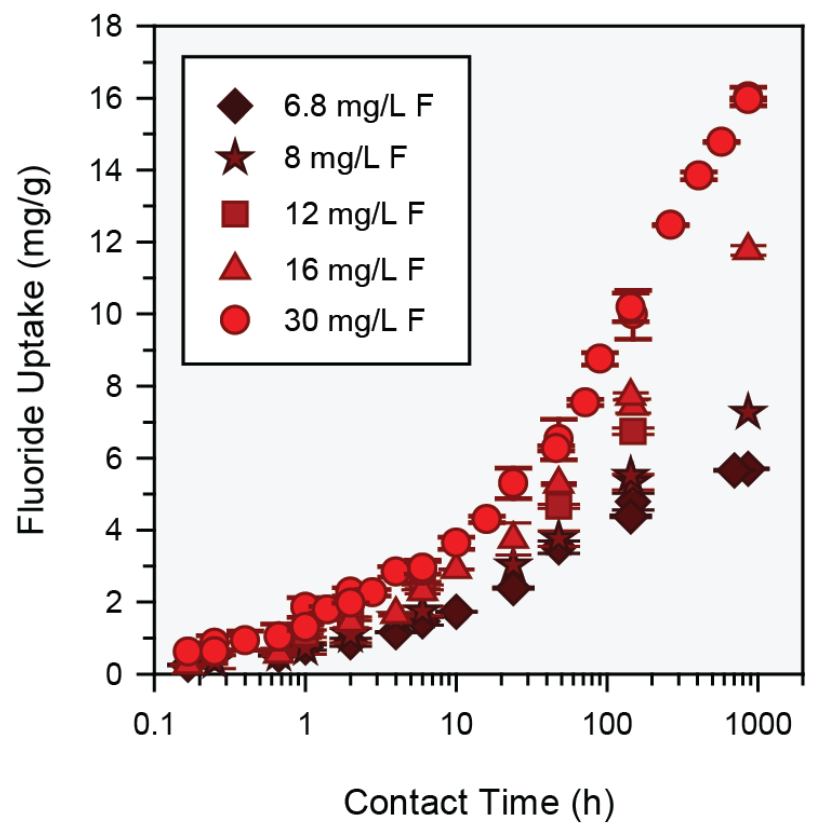

Figure S1. Fluoride uptake for DCBR tests with various influent fluoride concentrations.

Dissolved calcium (figure S2-a) was measured with a Thermo Scientific Orion Ionplus SureFlow calcium electrode (Model 9700 BNWP). Total phosphate (figure S2-b) measurements were performed with a Hach D/890 Colorimeter and using the orthophosphate ascorbic acid method. $\mathrm{pH}$ (figure S2-e) was measured using a Fisher Scientific Accumet double junction pH electrode. Both $\mathrm{pH}$ and calcium probes were calibrated ( 3 points) before each use, and the colorimeter was checked for accuracy before batch tests by using a phosphate standard solution (Hach). The carbonate concentration (figure S2-d) was measured using titration with $\mathrm{HCl}$ and the $\mathrm{pH}$ meter, where the total alkalinity was the amount of acid added to drop the $\mathrm{pH}$ to 4.5. The total 
carbonate concentration was determined from the total alkalinity after factoring in the contribution from phosphate. The details of each measurement has been reported previously ${ }^{1}$, and are all Standard Methods ${ }^{2}$. The ionic strength was calculated knowing all of the solute concentrations, including the added $\mathrm{NaCl}$, assuming that its concentration did not change.
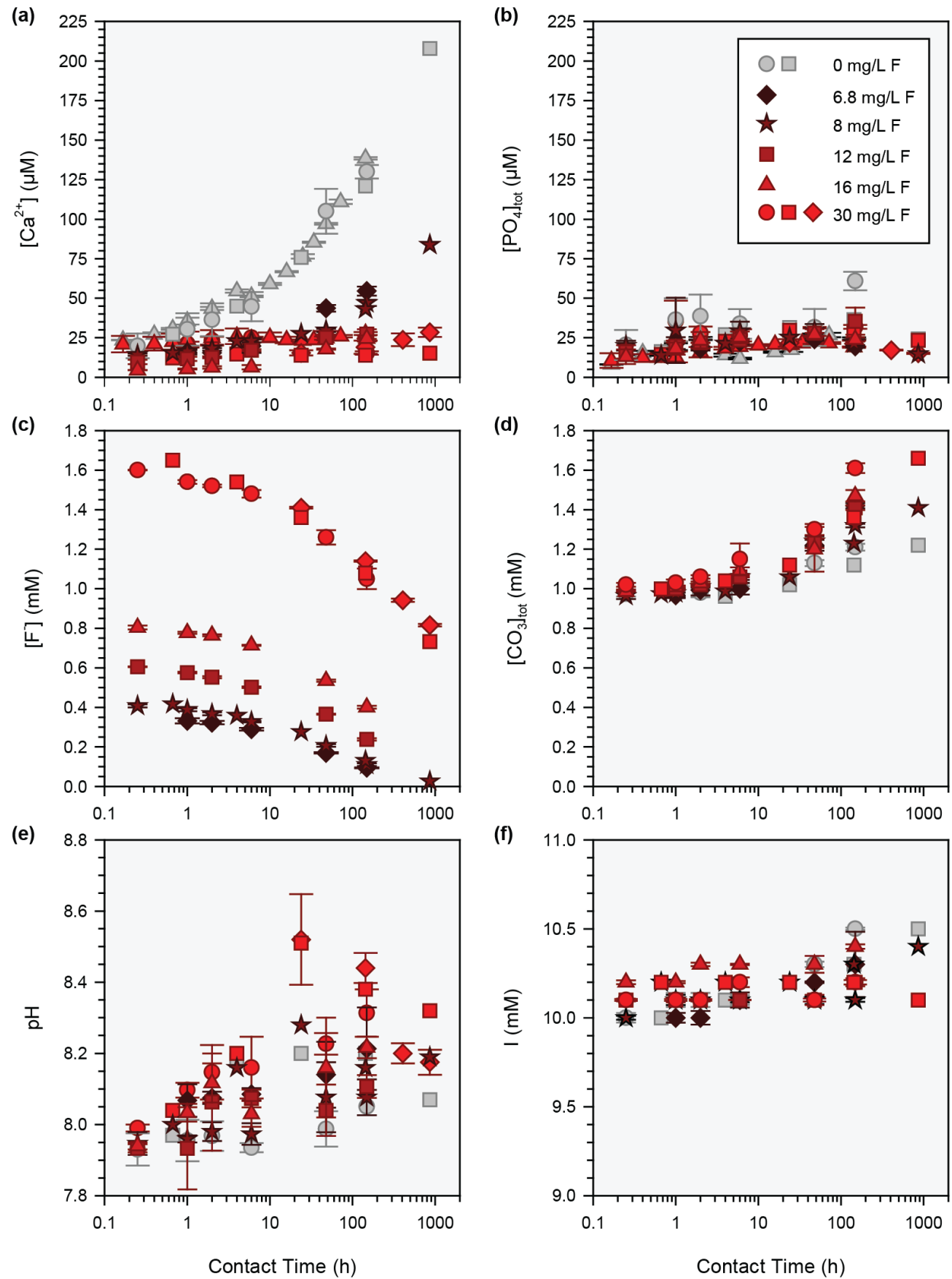

Figure S2. Solute concentrations for DCBR tests of various fluoride concentrations. 
Activity coefficients for monovalent to trivalent ions were calculated according to the Davies equation ${ }^{3}$,

$$
\gamma_{\mathrm{z}}=10^{\wedge}\left[-0.51 * \mathrm{Z}^{2}\left(\frac{\sqrt{\mathrm{I}}}{1+\sqrt{\mathrm{I}}}+0.2 \mathrm{I}\right)\right]
$$

where $\mathrm{Z}$ is the ionic species' formal charge. Ion activity products (IAP) of HAP (figure S3-a):

$I_{\text {APAP }}=\left\{\mathrm{Ca}^{2+}\right\}^{5}\left\{\mathrm{PO}_{4}{ }^{3-}\right\}^{3}\left\{\mathrm{OH}^{-}\right\} ;$FAP (figure S3-b): IAP FAP $=\left\{\mathrm{Ca}^{2+}\right\}^{5}\left\{\mathrm{PO}_{4}{ }^{3-}\right\}^{3}\left\{\mathrm{~F}^{-}\right\}$and fluorite (figure S3-c): $\mathrm{IAP}_{\mathrm{CaF}_{2}}=\left\{\mathrm{Ca}^{2+}\right\}\left\{\mathrm{F}^{-}\right\}^{2}$ were calculated using the solute activities. For the DCBR tests with initial $\mathrm{F}^{-}$ concentration of $30 \mathrm{mg} / \mathrm{L}$ the saturation index (S) was calculated (figure S3-d) for FAP, HAP, fluorite as well as other calcium phosphate and calcium minerals, including francolite $\left(\mathrm{Ca}_{10}\left(\mathrm{PO}_{4}\right)_{5}\left(\mathrm{CO}_{3}\right) \mathrm{OH}_{0.28} \mathrm{~F}_{2.72}\right)^{4}$, octacalcium phosphate $\left(\mathrm{OCP}, \mathrm{Ca}_{4} \mathrm{H}\left(\mathrm{PO}_{4}\right)_{3} \cdot 3 \mathrm{H}_{2} \mathrm{O}\right)^{5}$, amorphous calcium phosphate $\left(\mathrm{ACP},\left[\mathrm{Ca}_{2}\left(\mathrm{HPO}_{4}\right)_{3}\right]^{2-}\right)^{6}$, dicalcium phosphate dihydrate (DCPD, $\left.\mathrm{CaHPO}_{4} \cdot 2 \mathrm{H}_{2} \mathrm{O}\right)^{7}$, and calcite $\left(\mathrm{CaCO}_{3}\right)^{3}$ using the following equation:

$$
S=\log \left(\frac{I A P}{K_{S 0}}\right)^{1 / v}
$$

where $v$ is the number of growth units in the solid. Values between -1 and 1 are close to saturation, and supersaturation is any value above 0 . 

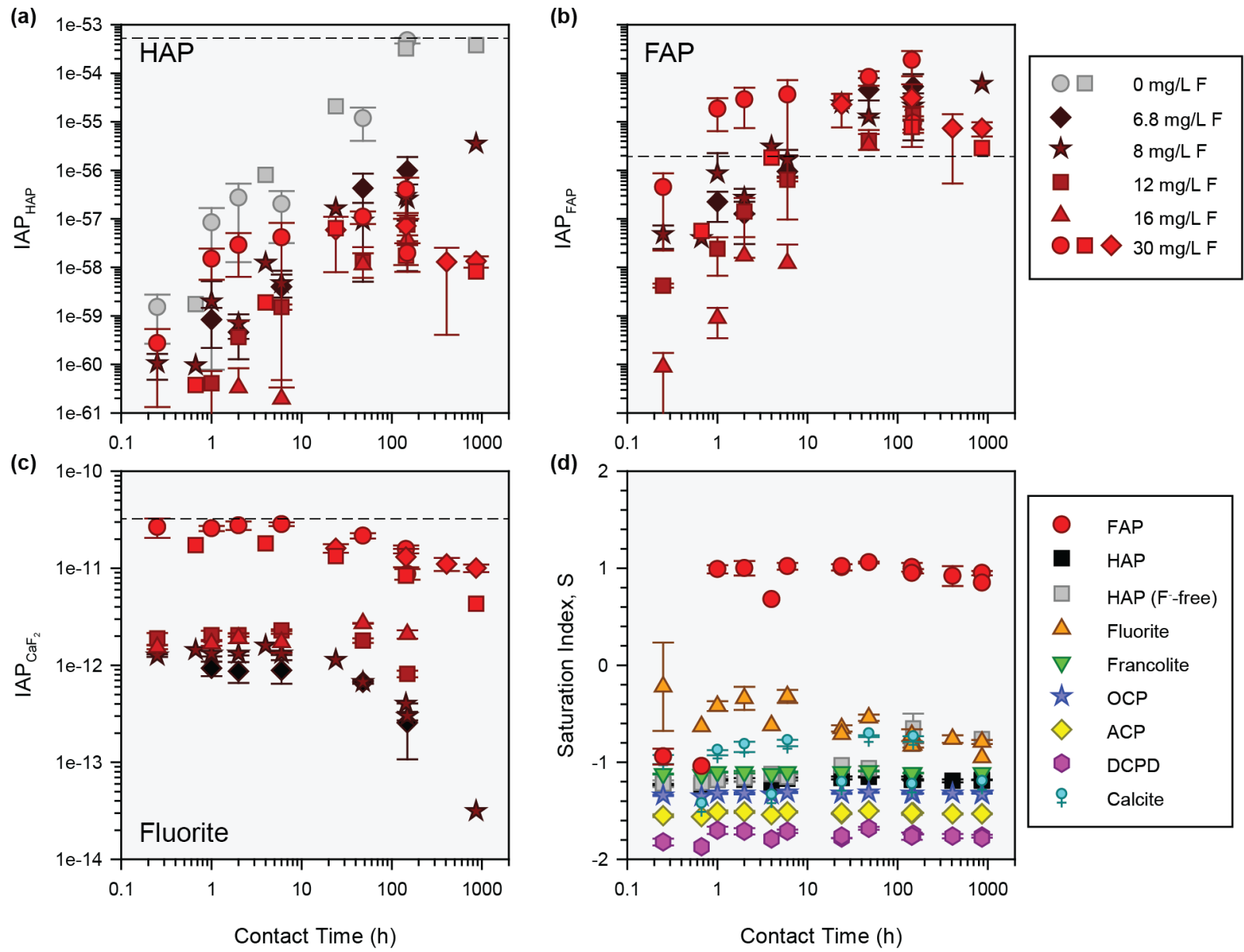

Figure S3. Ion activity products of (a) HAP, (b) FAP, and (c) $\mathrm{CaF}_{2}$. Note that the vertical scale of (a) and (b) are equal. The IAP of HAP is shown for both the control (without F-) and fluoridated solutions. The horizontal dashed line in (a) corresponds to the thermodynamic solubility product $\left(\log \mathrm{K}_{\mathrm{SO}, \mathrm{HAP}}=-53.28\right)^{8}$ of a relatively high solubility HAP. Similar lines in $(\mathbf{b})\left(\log \mathrm{K}_{\mathrm{s} 0, \mathrm{FAP}}=-55.71\right)^{8}$ and (c) $\left(\log \mathrm{K}_{\mathrm{s} 0, \mathrm{CaF} 2}=-10.50\right)^{3}$ are depicted for the solubility products of a relatively high solubility FAP and a typical value for $\mathrm{CaF}_{2}$, respectively. Note that none of the $\mathrm{IAP}_{\mathrm{CaF} 2}$ values exceed $\mathrm{K}_{\mathrm{s} 0, \mathrm{CaF} 2}$. (d) Shows the temporal saturation index $(S)$ of a wide range of calcium phosphates, including francolite $\left(\log \mathrm{K}_{\mathrm{s} 0, \mathrm{Francolite}}=-103\right)^{4}, \mathrm{OCP}\left(\log \mathrm{K}_{\mathrm{s} 0, \mathrm{OCP}}=-48.4\right)^{5}, \mathrm{ACP}\left(\log \mathrm{K}_{\mathrm{s} 0, \mathrm{ACP}}=-16.09\right)^{6}, \mathrm{DCPD}$ $\left(\log \mathrm{K}_{\mathrm{S} 0, \mathrm{DCPD}}=-6.68\right)^{7}$ as well as calcite $\left(\log \mathrm{K}_{\mathrm{s} 0, \text { calcite }}=-8.48\right)^{3}$. 


\section{SECTION S3. HAP CHARACTERIZATION}

\section{Composition Analysis}

Elemental analysis was carried out using inductively coupled plasma mass spectrometry (ICPMS) at the School of Chemical Sciences (SCS) at the University of Illinois at Urbana-Champaign (UIUC), using an ELAN DRC-e ICP-MS instrument. Quantitative ICP-MS was used principally to measure the percent weight of calcium and phosphorus.

Because this HAP was synthesized with industrial grade chemicals, we addressed the concern that it could contain a significant amount of contamination. Evidence of some carbonaceous residue is shown in HAP using the ATR-FTIR spectra (see figure S5 and discussion below). This contaminant carbon - amounting to a small fraction ( $0.1 \mathrm{wt} . \%)$ of the material - is removed before $500{ }^{\circ} \mathrm{C}$. Additionally, trace amounts of $\mathrm{Na}(0.25 \%$ wt.), $\mathrm{Mg}(0.62 \%$ wt.), Fe (0.14\% wt.), and $\operatorname{Sr}(0.14 \%$ wt.) were found using ICP-MS. Of the 45 metal elements measured, only these four were present in the ppm range. Otherwise, no significant contamination was found. Notably, the Na content is an order of magnitude lower compared with apatites considered to be Na-bearing carbonated HAPs, where $\mathrm{Na}^{+}$ions play a significant role in charge balance lattice substitutions ${ }^{9}$.

Carbon and hydrogen content (ascribed to carbonate and water) were measured with an Exeter Analytical CHN analyzer (Model CE 440) at the SCS at UIUC. Samples weighing approximately $10 \mathrm{mg}$ were placed in aluminum capsules inside a glovebox with a nitrogen atmosphere, then injected into a high temperature furnace heated to $1000^{\circ} \mathrm{C}$ in oxygen. The combustion products are passed through a series of reagents and scrubbers to reduce them to $\mathrm{CO}_{2}$ and $\mathrm{H}_{2} \mathrm{O}$ and measured by passing through a series of high-precision conductivity detectors 
coupled with $\mathrm{CO}_{2}$ and $\mathrm{H}_{2} \mathrm{O}$ traps, respectively. Detection limits of samples of this size can reach to $0.02 \%$ wt. for both $\mathrm{C}$ and $\mathrm{H}$.

Prior to ICP and $\mathrm{CH}$ analyses samples were sieved to $<32 \mu \mathrm{m}$, heated to $160^{\circ} \mathrm{C}$ under vacuum, purged with $\mathrm{N}_{2}$, and stored in airtight glass vials. This was done to remove physisorbed water and provide an effective baseline for water quantification.

Table S1 shows the results of the ICP-MS (for $\mathrm{Ca}$ and $\mathrm{P}$ ) and $\mathrm{CH}$ analyses for four separate samples of HAP. To assess HAP's composition, we first considered the location of the carbonate substitution. Hydroxyapatite synthesized at low temperatures and in the presence of air primarily incorporate carbonate within its crystal structure by replacing phosphate ions in the lattice, a B-type substitution, rather than replacing hydroxide ions in the $\mathrm{OH}^{-}$channel sites (Atype substitution). Many have used infrared spectroscopy to assign particular C-O bending mode peaks to the substitution type, but a recent study cast doubt over most assignments ${ }^{10}$. Nevertheless, apatite carbonate $v_{2}$ bands are generally considered to exhibit characteristic fingerprints at $872-875 \mathrm{~cm}^{-1}$ for B-type and $880 \mathrm{~cm}^{-1}$ for A-type carbonate substitutions ${ }^{11}$. The $v_{2}$ band of our HAP was at $874 \mathrm{~cm}^{-1}$ (figure S5) confirming a B-type substitution. Furthermore, a B-type carbonate substitution explains why the $\mathrm{Ca} / \mathrm{P}$ ratios are greater than the stoichiometric value because of the replacement of phosphate ${ }^{12-14} \cdot{ }^{13} \mathrm{C}$ direct polarization (DP) and ${ }^{1} \mathrm{H} \rightarrow{ }^{13} \mathrm{C}$ cross polarization (CP) solid-state Nuclear Magnetic Resonance (NMR) spectroscopy helps to confirm the carbonate substitution assignment. ${ }^{13} \mathrm{C}$ DP (recycle delay of 120 s, 512 scans) and ${ }^{1} \mathrm{H} \rightarrow{ }^{13} \mathrm{C} \mathrm{CP}$ (5 ms contact time, 20480 scans, 1 s recycle delay) NMR spectra of untreated HAP were acquired (see figure S9). ${ }^{1} \mathrm{H}-{ }^{13} \mathrm{C} C P$ NMR, which is typically used to determine apatitic carbonate ${ }^{9,15,16}$, produced an asymmetric resonance. Comparison with the ${ }^{13} \mathrm{C}$ DP spectrum led 
us to conclude the presence of two peaks at $172.2 \mathrm{ppm}$ and $170.4 \mathrm{ppm}$ (both with FWHM=325 $\mathrm{Hz}$ ) that are present in equal amounts (DP deconvolution) and have different cross polarization dynamics (CP deconvolution). The peak at $170.4 \mathrm{ppm}$ is considered to indicate B-type carbonate ${ }^{9,15,16}$. A-type substitutions have been assigned to ${ }^{13} \mathrm{C}$ resonances lower than the Btype resonance, or $<170 \mathrm{ppm}^{9,15,16}$. Therefore, though the literature does not provide a precedent for an apatite carbonate peak at $172.2 \mathrm{ppm}$, it is likely a B-type substitution. Certainly, our FTIR and NMR spectra does not support the presence of A-type carbonate in HAP. Because carbonate does not decompose in HAP until around $600^{\circ} \mathrm{C}^{12}$, the composition of HAP heated to $500{ }^{\circ} \mathrm{C}$ is assumed not to change except for the loss of water; however, some $\sim 0.1 \%$ wt. carbon is lost upon heating to $500{ }^{\circ} \mathrm{C}$, indicating the presence of some carbonaceous contamination. A small and broad peak at $1639 \mathrm{~cm}^{-1}$ is present in HAP without heat treatment but disappears after heating to $500{ }^{\circ} \mathrm{C}$. One study attributes this peak to surface water ${ }^{17}$, but it could perhaps belong to trace organics from the synthesis water. Therefore, the unit cell carbonate occupancy for HAP is calculated using the wt. \% of carbon measured in HAP heat treated to $500{ }^{\circ} \mathrm{C}$. It was assumed that all measured phosphorus was in the form of $\mathrm{PO}_{4}{ }^{3-}$, all $\mathrm{H}$ belonged to water, and all carbon lost after heating above $500^{\circ} \mathrm{C}$ belonged to $\mathrm{CO}_{3}{ }^{2-}$ incorporated into the apatite lattice. The trace metals were not considered when calculating the unit cell stoichiometry.

The overall apatite composition was first calculated based on either a full occupancy of calcium sites or phosphate sites, according to whether the fraction $\mathrm{Ca} /\left(\mathrm{PO}_{4}+\mathrm{CO}_{3}\right)$ was greater or lesser than 5/3. Hence, the amount of $\mathrm{OH}^{-}$ions is intuited as the amount that satisfies the 
charge neutrality rule. This method as demonstrated by Marcovic et al. ${ }^{18}$ works well for stoichiometric apatites.

Table S1. Results of elemental analyses for HAP $(\mathrm{N}=4)$ and calculated unit cell stoichiometry.

Results: wt\%

\begin{tabular}{cccc|ccccc}
$\mathrm{Ca}$ & $\mathrm{P}$ & $\mathrm{C}^{*}$ & $\mathrm{H}^{+}$ & $\mathrm{Ca}$ & $\mathrm{PO}_{4}$ & $\mathrm{CO}_{3}$ & $\mathrm{OH}$ & $\mathrm{H}_{2} \mathrm{O}^{\ddagger}$ \\
\hline 35.31 & 14.29 & 1.22 & 0.428 & 9.39 & 4.92 & 1.08 & 1.86 & 1.35 \\
\pm 0.91 & \pm 0.35 & \pm 0.07 & \pm 0.01 & \pm 0.11 & \pm 0.05 & \pm 0.05 & \pm 0.19 & \pm 0.10 \\
\hline
\end{tabular}

${ }^{*}$ The stoichiometry of HAP was calculated using the carbon wt. \% measured from HAP heat treated at $500{ }^{\circ} \mathrm{C}$ for 6 $\mathrm{h}$, because carbon loss under $500{ }^{\circ} \mathrm{C}$ cannot be attributable to lattice carbonate. ${ }^{\dagger}$ The measured wt. $\%$ of $\mathrm{H}$ (corresponding to water wt. \% of $3.73 \pm 0.11$ ) for HAP is technically for HAP heated to $160{ }^{\circ} \mathrm{C}$ because of how the samples were prepared. This agrees well with the TGA analysis in figure $\mathrm{S} 5$ where $3.2 \mathrm{wt} \%$ water is lost between 160-350 ${ }^{\circ} \mathrm{C}$. HAP heated between $50-350{ }^{\circ} \mathrm{C}$ loses $\sim 8$ wt. \% water (see figure S5). ${ }^{\ddagger}$ Given that adsorbed water is thought to be completely removed by $200^{\circ} \mathrm{C}$, the water lost after that is mostly considered structural. So the $\sim 2.1$ wt. \% water considered structural amounts to $\sim 1.35$ water molecules/unit cell, close to the outcome that was determined by Pasteris and coworkers ${ }^{19}$.

However, due to the charge balance substitutions that take place with B-type carbonate apatites, other methods have been used to calculate non-stoichiometric apatite composition based on the amount of introduced carbonate. McElderry et al. ${ }^{13}$ introduced a formula for Btype carbonated hydroxyapatites synthesized with low $\mathrm{Na}^{+}$substitutions and at high $\mathrm{pH}$ (low incorporation of $\mathrm{HPO}_{4}{ }^{2-}$ ), similar to our HAP:

$$
\mathrm{Ca} a_{10-x y}\left(\mathrm{PO}_{4}\right)_{6-x}\left(\mathrm{CO}_{3}\right)_{x}(\mathrm{OH})_{2-x(2 y-1)}
$$

where $\mathrm{x}$ represents the molar amount of carbonate substituted in the unit cell for phosphate and $y$ represents the fraction of calcium loss proportional to $x$. Charge neutrality is still maintained by hydroxide occupancy. They found that the amount of calcium and hydroxide ion loss is dependent on the carbonate concentration where a low-loss substitution (0.625 Ca per $\mathrm{CO}_{3}$ ) mechanism dominates for low carbonate incorporation up to $6.5 \mathrm{wt}$. \% followed by a mid (1 $\mathrm{Ca}$ per $\left.\mathrm{CO}_{3}\right)$ to high-loss (1.25 $\mathrm{Ca}$ per $\mathrm{CO}_{3}$ ) substitution mechanism at higher carbonate levels. Our apatite has $6.5 \mathrm{wt}$ \% carbonate and, hence, is at this transition point. This means that the 
calcium and hydroxide stoichiometry could be within a wide variance of values. Using the lowloss substitution mechanism, our HAP would have a composition of Ca9.33 $\left(\mathrm{PO}_{4}\right)_{4.92}\left(\mathrm{CO}_{3}\right)_{1.08}(\mathrm{OH})_{1.73 .}$ By contrast the mid-loss mechanism would produce a stoichiometry of $\mathrm{Ca}_{8.92}\left(\mathrm{PO}_{4}\right)_{4.92}\left(\mathrm{CO}_{3}\right)_{1.08}(\mathrm{OH})_{0.92}$ and the high-loss mechanism would produce a stoichiometry of $\mathrm{Ca}_{8.65}\left(\mathrm{PO}_{4}\right)_{4.92}\left(\mathrm{CO}_{3}\right)_{1.08}(\mathrm{OH})_{0.65}$. Either way, the amount of calcium is less than the levels needed to match the Ca/P ratio as determined by ICP-MS analyses and the relative amount of $\mathrm{OH}^{-}$drops substantially, although the low-loss substitution mechanism is most similar to the stoichiometry calculated by the Marcovic et al. method. One way to navigate this discrepancy is to use an alternative characterization technique to validate the stoichiometry. We used quantitative ${ }^{1} \mathrm{H}$ direct polarization (DP) NMR to look at the amount of $\mathrm{OH}^{-}$in our HAP compared with a HAP reference standard. In DP NMR the mass normalized signal area of a chemical species directly correlates to the amount of that species in the sample. Furthermore, the $\mathrm{OH}^{-}$signal $(0.0 \mathrm{ppm})$ is clearly distinct from the $\mathrm{H}_{2} \mathrm{O}$ signal $(6.0 \mathrm{ppm})$ in NMR and can be easily deconvoluted. After factoring in the sample masses, the signal ratio of $\mathrm{OH}_{\text {sample }}^{-} / \mathrm{OH}^{-}$standard was $\sim 0.55$ (see spectra in figure S19). The resulting stoichiometry of our HAP, considering that it contains $55 \%$ of the stoichiometric amount of $\mathrm{OH}^{-}$, is therefore $\mathrm{Cag}_{9.01}\left(\mathrm{PO}_{4}\right)_{4.92}\left(\mathrm{CO}_{3}\right)_{1.08}(\mathrm{OH})_{1.10}$, which lands somewhere in between the low-loss and mid-loss ion substitution mechanisms. This conclusion supports the possibility that our HAP contains excess calcium, probably located at the surface of the NPs in the ACP layer. These calciums might be charge balanced by counterions used during HAP synthesis, such as $\mathrm{Cl}^{-}$. We assume this because the zeta potential of our HAP at $\mathrm{pH} 8$ in water was $\sim 1 \pm 5 \mathrm{mV}$, or effectively uncharged (data not shown). 


\section{X-ray Diffraction}

Powder X-ray diffraction (XRD, figureS4) was performed using a Siemens/Bruker D-5000 X-ray diffractometer with a Cu $\mathrm{K}_{\alpha}$ radiation source emitting at a wavelength of $0.15418 \mathrm{~nm}$. Samples were scanned between $10^{\circ}-70^{\circ}(2 \theta)$ at a scan rate of $1^{\circ} / \mathrm{min}$ and increments of $0.02^{\circ}$. Analysis of the X-ray pattern was performed using Jade software (version 9.0). The International Centre for Diffraction Data (ICDD) database was used for peak matching, and the Whole Pattern Fitting (WPF) Rietveld refinement method was used for phase and unit cell dimension analyses. No $\mathrm{CaF}_{2}$ phase was detected by WPF. The unit cell values for untreated HAP were determined to be $a=9.404 \pm 0.005 \AA$ and $c=6.893 \pm 0.004 \AA$, whereas the parameters for the HAP standard

were $a=9.411 \AA$ and $c=6.890 \AA$. The unit cell values for fluoridated HAP were also determined for a range of treatment times to observe how they might evolve with fluoridation. These samples were dried out at $50^{\circ} \mathrm{C}$ for 2 days prior to grinding and sieving below $150 \mu \mathrm{m}$. As a control, an untreated HAP sample was also dried at $50{ }^{\circ} \mathrm{C}$ for 2 days, its diffraction pattern acquired, and its unit cell parameters subsequently refined. No statistically significant difference in the unit cell parameters was observed between this control $(a=9.405 \pm 0.004 \AA$ and $c=6.891 \pm 0.002 \AA$ ) and the raw HAP material. 

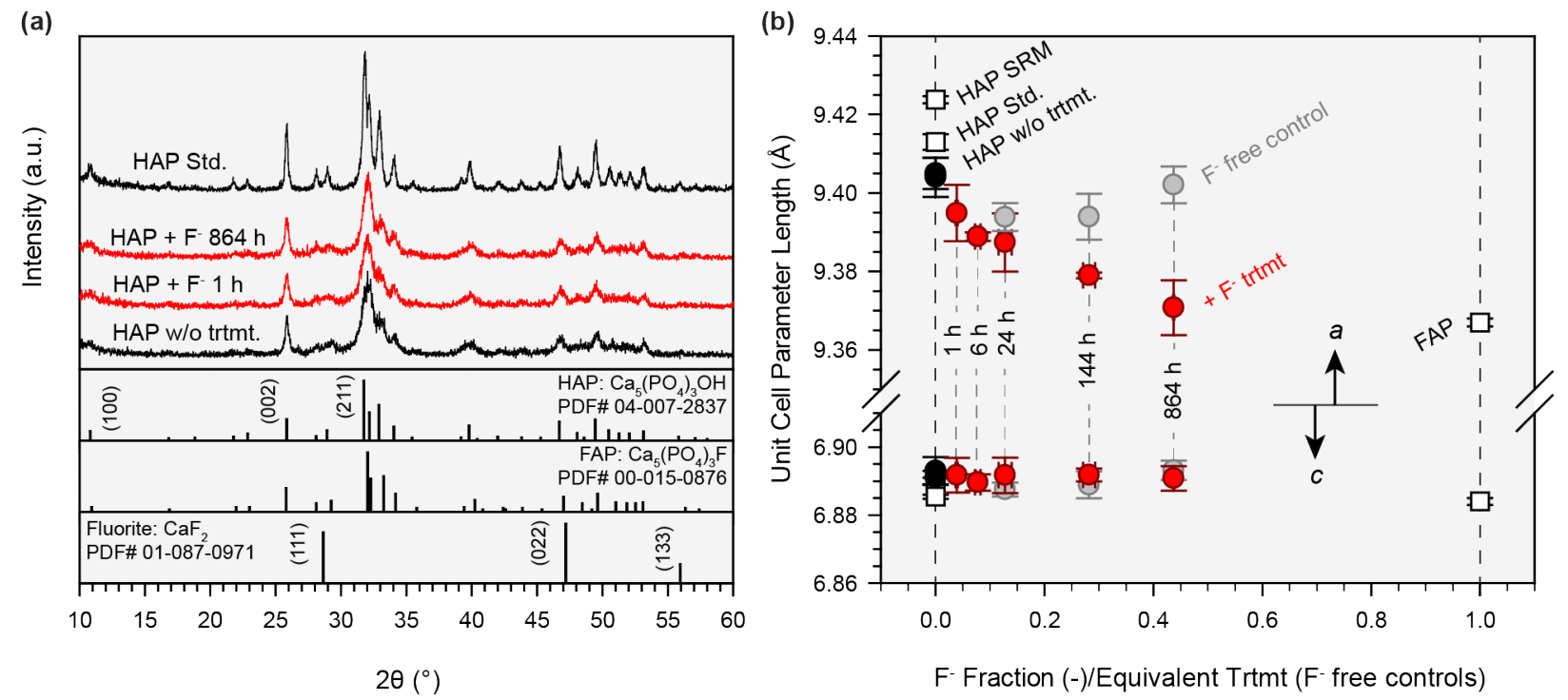

Figure S4. (a) X-ray diffraction patterns of powder made from untreated HAP pellets (bottom), AP after fluoridation ([F- $\left.]_{\text {initial }}=30 \mathrm{mg} / \mathrm{L}, \mathrm{pH} 8\right)$ at $1 \mathrm{~h}$ and $864 \mathrm{~h}$ (middle patterns in red), and a HAP standard (top) synthesized according to Marcovic et al. ${ }^{18}$. The powder diffraction files (PDFs) at the bottom of the figure were acquired from the ICDD database. (b) Depiction of Rietveld refined $a$ and $c$ unit cell parameters as a function of $\mathrm{F}^{-}$fraction for fluoridated HAP (in red). $\mathrm{F}^{-}$ fraction was calculated as experimental DCBR test $\mathrm{F}^{-}$uptake divided by total $\mathrm{F}^{-}$capacity ( 37.74 $\mathrm{mg} / \mathrm{g}$ ). The unit cell parameters of control batch test HAPs that are $\mathrm{F}^{-}$-free are also depicted (in grey) alongside the fluoridated samples of the same treatment time. The black circles represent the unit cell parameters for untreated HAP and HAP heated to $50^{\circ} \mathrm{C}$ (i.e. the temperature that the treated AP samples were dried at) and are overlapping. The white squares represent the unit cell parameters for a HAP standard reference material (SRM, produced by the National Institute of Standards \& Technology ${ }^{18}$ ) and for a stoichiometric FAP ${ }^{20}$, along with our internally synthesized standard whose pattern is shown in (a).

\section{Fourier Transform Infrared Spectroscopy}

A PerkinElmer, Frontier, and Pike Technologies GladiATR attenuated total reflectance Fourier transform infrared spectrometer (ATR-FTIR) was used to acquire IR transmittance spectra in the range of $400-4000 \mathrm{~cm}^{-1}$, depicted in figure S5. HAP heat treated to $500^{\circ} \mathrm{C}$ and the HAP standard was measured in ambient air as quickly as possible after being vacuum purged in an $\mathrm{N}_{2}$ atmosphere at $160^{\circ} \mathrm{C}$, while the fluoridated HAP for $864 \mathrm{~h}$ was dried at $50^{\circ} \mathrm{C}$. Untreated 
HAP was not dried or purged. Spectra were averaged over 12 scans with a resolution of $0.5 \mathrm{~cm}^{-}$

1. Spectrum software was used for baseline correction and peak analysis.

Phosphate vibrational modes dominate the $500-1150 \mathrm{~cm}^{-1}$ region $^{10}$, although the $v_{2}$ carbonate bending mode is at $870-880 \mathrm{~cm}^{-1}$. The $v_{3}$ carbonate stretching mode absorbs at $1415-1460 \mathrm{~cm}^{-1}$. A broad, asymmetric $\mathrm{O}-\mathrm{H}$ stretching mode peak spanning from $2700-3650$ $\mathrm{cm}^{-1}$ is indicative of bound water, while the narrow peak at $3571 \mathrm{~cm}^{-1}$ corresponds to columnar $\mathrm{OH}^{-}$ions in the HAP lattice ${ }^{19}$. The large amount of water in the samples appears to drown out the $\mathrm{OH}^{-}$signal, and made for a poor way to achieve quantitation for our samples.

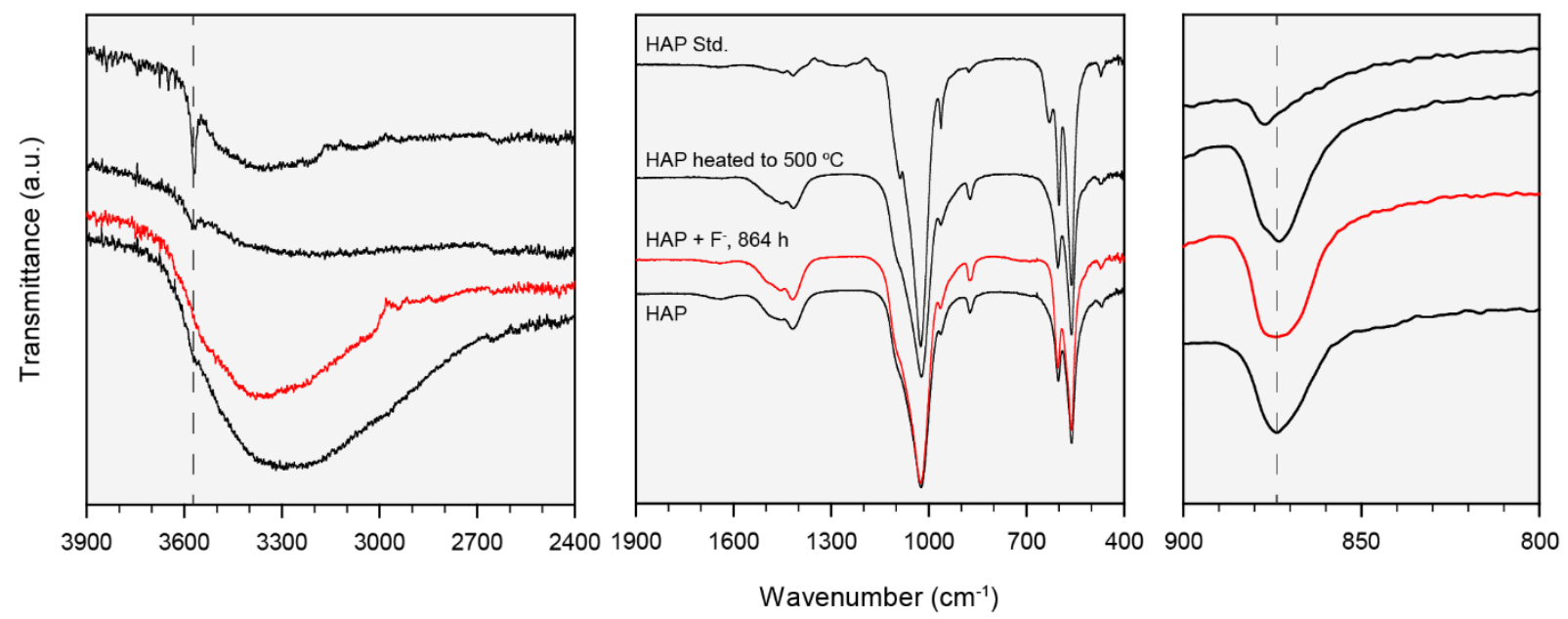

Figure S5. FTIR spectra of HAP without heat treatment, HAP after $864 \mathrm{~h}$ fluoridation and dried at $50{ }^{\circ} \mathrm{C}\left(30 \mathrm{mg}-\mathrm{F} / \mathrm{L}\right.$ initial concentration), HAP heat treated to $500{ }^{\circ} \mathrm{C}$, and the HAP standard referred to in figure S4. Spectra are plotted in the ranges of $2400-3900 \mathrm{~cm}^{-1}, 400-1900 \mathrm{~cm}^{-1}$, and $800-900 \mathrm{~cm}^{-1}$ from left to right. Dashed lines at $3571 \mathrm{~cm}^{-1}$ and $874 \mathrm{~cm}^{-1}$ denote the characteristic resonance frequencies of columnar $\mathrm{OH}$ stretch mode and the $v_{2}$ bending mode of B-type $\mathrm{CO}_{3}$.

\section{Thermogravimetric Analysis}

Thermogravimetric analysis (TGA) was conducted at the MRL-UIUC using a Q50 TGA (figure S6). Roughly $100 \mathrm{mg}$ of HAP powder was placed in an aluminum pan and purged under an $\mathrm{N}_{2}$ atmosphere prior to heating. The previously untreated sample was held at $30^{\circ} \mathrm{C}$ for two 
minutes during purging prior to ramping the temperature at $10^{\circ} \mathrm{C} / \mathrm{min}$ to until it reached the target temperature of $350^{\circ} \mathrm{C}$. Universal Analysis software was used to process the data.

According to LeGeros et al..$^{21}$ and more recent works ${ }^{19,22,23}$, the amount of adsorbed or surface water is equivalent to the mass loss between $50-200{ }^{\circ} \mathrm{C}$, while structural water is equivalent to the mass lost from $200-550{ }^{\circ} \mathrm{C}$. Work by Ivanova et al. ${ }^{24}$ found that all structural water is lost after $350^{\circ} \mathrm{C}$, so that is the metric we used here.

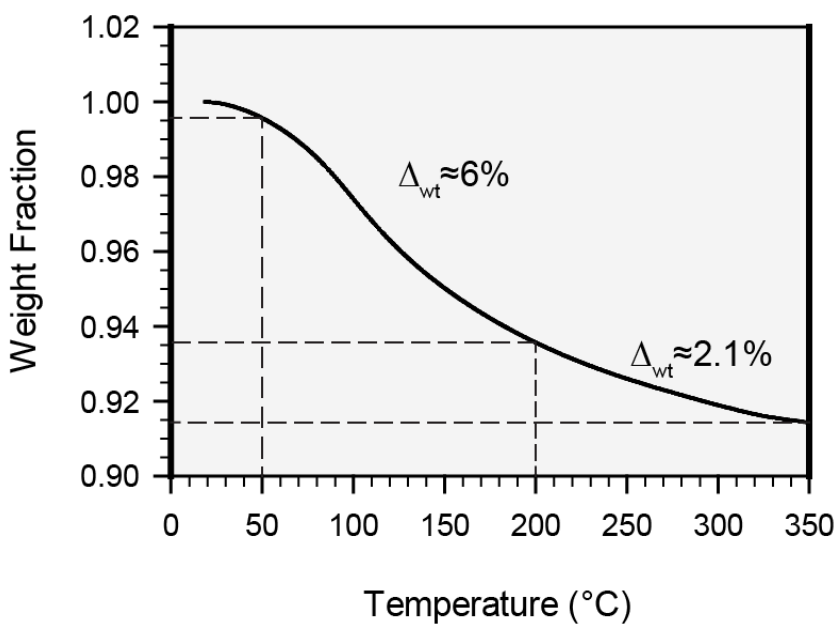

Figure S6. Normalized mass loss of HAP with increasing temperature.

\section{$\mathrm{N}_{2}$ Isotherm Analysis}

$\mathrm{N}_{2}$ isotherms were acquired with a Micromeretics ASAP 2020 surface analyzer (figure S7-a). Pellets were used rather than powder. All samples were degassed under vacuum at $300{ }^{\circ} \mathrm{C}$ for 12 hours prior to analysis. It was confirmed, as observed by others ${ }^{17}$, that the SSA of HAP is not affected over this temperature range (data not shown). Brunauer-Emmett-Teller (BET) SSA analyses on several samples were performed using Microactive v. 4.03 software (figure S8).

The pore size distribution was also modeled using the Barrett, Joyner, and Halenda (BJH) procedure using the desorption isotherm data and a Halsey-Faas correction (figure S7-b). The 
maximum pore size for HAP was between $30-40 \mathrm{~nm}$ (in the mesoporous region), which is on the order of the size of the HAP NPs. Hence, the pellet pores seem to consist mainly of interparticle space from closely packed HAP NPs. Since $\mathrm{N}_{2}$ sorption can only detect the micro $(<$ $2 \mathrm{~nm}$ ) and mesoporous ( $2 \mathrm{~nm}<\mathrm{d}<50 \mathrm{~nm}$ ) space, we do not have an accurate understanding of the macropore architecture of the pellets.

(a)

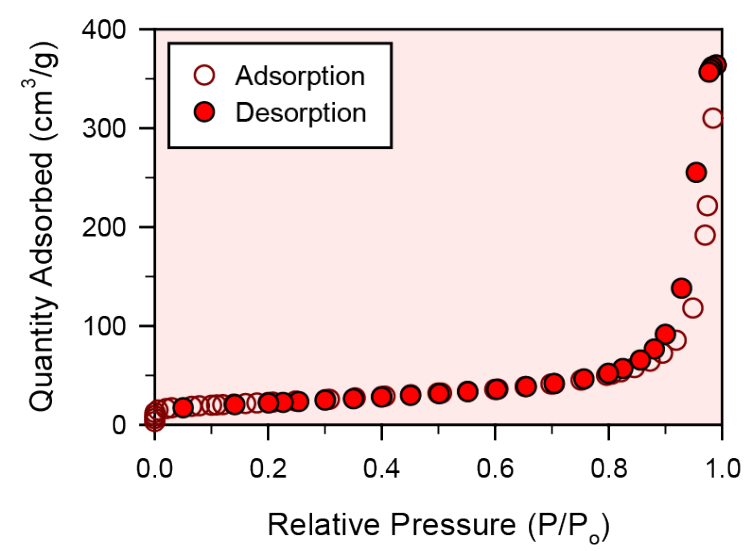

(b)

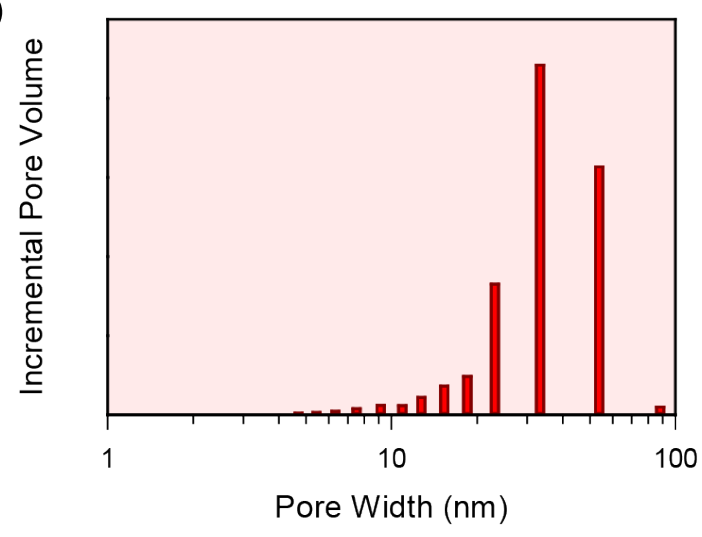

Figure S7. (a) $\mathrm{N}_{2}$ adsorption and desorption isotherms for untreated HAP; and resulting (b) BJH pore size distribution.

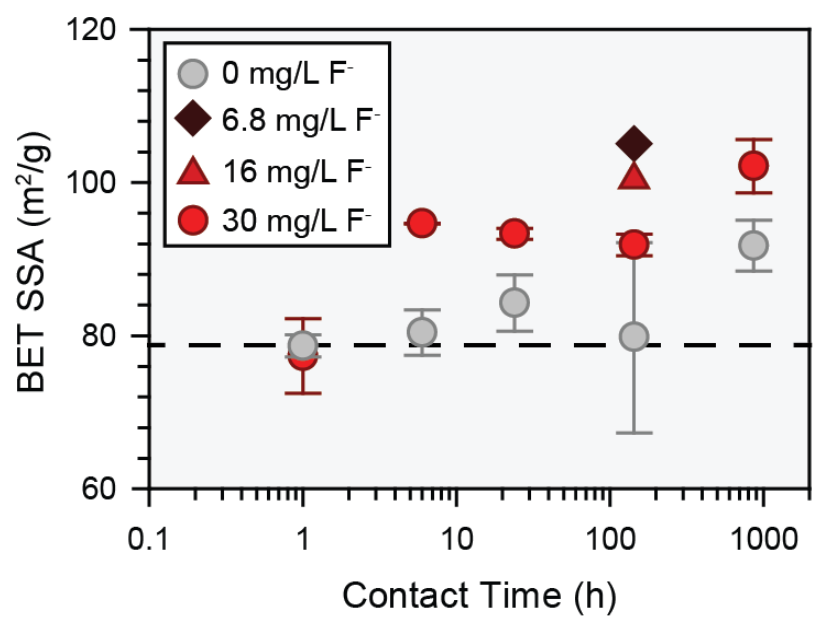

Figure S8. BET SSA of HAP pellets $(n=2)$ before treatment (horizontal line) and over the course of batch tests (data points) with and without $\mathrm{F}^{-}$. Measurements for tests with initial $\mathrm{F}^{-}$ concentrations of 6.8 and $16 \mathrm{mg} / \mathrm{L} \mathrm{F}$ at $144 \mathrm{~h}$ treatment time are also included. 


\section{Nuclear Magnetic Resonance (NMR) Spectroscopy}

${ }^{19} \mathrm{~F}$ and ${ }^{13} \mathrm{C}$ solid-state magic-angle-spinning (MAS) NMR experiments were performed at the National High Magnetic Field Laboratory using a Bruker Avance $600 \mathrm{MHz}$ NMR spectrometer. After removal from batch tests, HAP pellets were vacuum dried at $50{ }^{\circ} \mathrm{C}$ for 2 days, then powdered with mortar and pestle and sieved with $124 \mu \mathrm{m}$ mesh and stored in air-tight glass vials in a vacuum desiccator until shipped to the NHMFL. Notably, Kreinbrink et al. ${ }^{25}$ observed non-specifically coordinated adsorbed $\mathrm{F}^{-}$species after heat-drying to $85^{\circ} \mathrm{C}$, thus, ensuring that our heat treatment would not alter the $\mathrm{F}^{-}$speciation. All ${ }^{19} \mathrm{~F}$ experiments were carried out operating at $564.68 \mathrm{MHz}$ resonance frequency, while ${ }^{13} \mathrm{C}$ experiments operated at $150.903 \mathrm{MHz}$ resonance frequency using either a $4 \mathrm{~mm}$ or $1.3 \mathrm{~mm}$ zirconia rotor. The ${ }^{19} \mathrm{~F}$ and ${ }^{13} \mathrm{C}$ direct polarization (DP), ${ }^{1} \mathrm{H} \rightarrow{ }^{13} \mathrm{C} \mathrm{CP}$, and ${ }^{19} \mathrm{~F} \rightarrow{ }^{13} \mathrm{C}$ heteronuclear correlation (HETCOR) experiments at $15 \mathrm{kHz}$ MAS spinning speeds were conducted using a $4 \mathrm{~mm}$ Bruker ${ }^{1} \mathrm{H}^{-19} \mathrm{~F}-\mathrm{X}$ CPMAS probe, while $40 \mathrm{kHz}$ MAS spinning speed ${ }^{19} \mathrm{~F}$ DP experiments utilized a Bruker ${ }^{1} \mathrm{H}-\mathrm{X} 1.3 \mathrm{~mm}$ MAS probe with the ${ }^{1} \mathrm{H}$ channel tuned to ${ }^{19} \mathrm{~F}$. Fluflenamic acid was used as the reference material for ${ }^{19} \mathrm{~F}$ and set to $-61.5 \mathrm{ppm}$ for reference. The ${ }^{13} \mathrm{C}$ reference material was glycine with which the carbonyl carbon resonance was referenced at $178.4 \mathrm{ppm}$.

The ${ }^{13} \mathrm{C}$ DP NMR experiment (figure S9) recorded 512 scans with a pulse length of $2.5 \mu \mathrm{s}$ ( $50^{\circ}$ flip-angle pulse), acquisition time of $10.30 \mathrm{~ms}$, and $120 \mathrm{~s}$ recycle delay. The ${ }^{1} \mathrm{H} \rightarrow{ }^{13} \mathrm{C} \mathrm{CP}$ experiment (figure S9) used a contact time of 5 ms, 1 s recycle delay, and recorded 20480 scans. The ${ }^{19} \mathrm{~F}$ DP NMR experiment at $15 \mathrm{kHz}$ MAS (figure S13) recorded 1024 scans with a pulse length of $1.0 \mu \mathrm{s}$ ( $25^{\circ}$ flip-angle pulse), acquisition time of $2.61 \mathrm{~ms}$, and $5 \mathrm{~s}$ recycle delay. Parameters for the $15 \mathrm{kHz}$ spin speed ${ }^{19} \mathrm{~F} \rightarrow{ }^{13} \mathrm{C}$ HETCOR experiment (figure S11) included a 
recycle delay of $2.5 \mathrm{~s}$, cross polarization contact time of $6 \mathrm{~ms}$, and 4096 scans for each of $32 \mathrm{t}_{1}$ increments.

The $2 \mathrm{D}{ }^{1} \mathrm{H} \rightarrow{ }^{19} \mathrm{~F}$ HETCOR experiment (figure S15) was performed on a Bruker Avance $600 \mathrm{MHz}$ wide-bore NMR spectrometer using a 4 mm Bruker HFX triple-resonance MAS probe. The sample spinning rate was controlled by a Bruker pneumatic MAS unit at $15 \mathrm{kHz} \pm 3 \mathrm{~Hz}$. The ${ }^{1} \mathrm{H}$ homo-nuclear decoupling was achieved using the phase-ramped frequency-switched LG sequence ${ }^{26}$ in the $t_{1}$ dimension with an $83.3 \mathrm{kHz} \mathrm{B}_{1}$ field, corresponding to $102.0 \mathrm{kHz}$ decoupling amplitude along the magic angle. A short contact time of $50 \mu$ s was used to transfer ${ }^{1} \mathrm{H}$ magnetization to ${ }^{19} \mathrm{~F}$ for detection under the SPINAL64 decoupling ${ }^{27}$ with a ${ }^{1} \mathrm{H}$ B ${ }_{1}$ field of $83 \mathrm{kHz}$. A total of $48 t_{1}$ increments were used. For each $t_{1}$ increment 640 scans were used to accumulate the signals with a recycle delays of 3 s. STATES was used for quadrature detection in the $t_{1}$ dimension ${ }^{28}$.

Experiments of ${ }^{19} \mathrm{~F}$ at $40 \mathrm{kHz}$ fast MAS spinning rate (figures 2 and S10,12,13) were conducted according to a multi-acquisition scheme described in detail formerly ${ }^{29}$. In brief, the ${ }^{19} \mathrm{~F} 90^{\circ}$ pulse length was calibrated to be $2.5 \mu$ s and the corresponding power level was used for all hard pulses and adiabatic inversion pulses. The pulse duration of $50 \mu$ s was used for the adiabatic inversion, whose waveform was achieved by using a 15\% apodized amplitude and $60 \mathrm{kHz}$ chirp frequency sweep. To ensure the quantification, all ${ }^{19} \mathrm{~F}$ DF experiments were performed using a small flip-angle pulse of $\sim 5^{\circ}$ and 5 acquisitions per scan with a total of 4096 scans for signal accumulation with a recycle delay of $1 \mathrm{~s}$ between scans.

To measure the transverse relaxation time $\mathrm{T}_{2}^{\prime}$ of incorporated $\mathrm{F}^{-}$ions at $40 \mathrm{kHz}$ spin speed, we employed the standard spin-echo pulse sequence, where the $180^{\circ}$ pulse length of $8.0 \mu$ s is 
applied in the middle of the echo time $\tau$ to refocus the incoherent contributions (such as field inhomogeneity, chemical shifts, etc.). The observed signal intensity as a function of $\tau$, as shown in figure $\mathrm{S} 14$, is used to fit the $\mathrm{T}_{2}^{\prime}$ value. The relaxation calculations of $\mathrm{F}^{-}{ }_{\mathrm{AP}}$ peak is also shown in figure S14.

All ${ }^{1} \mathrm{H}$ DP MAS NMR experiments (figures 2-c,d and S17-S19) were conducted at 7.04 T on a Varian Unity Inova spectrometer at the SCS NMR Facility of the UIUC, operating at resonance frequency of $\mathrm{v}_{0}\left({ }^{1} \mathrm{H}\right)=300.1 \mathrm{MHz} \mathrm{MHz}$ at room temperature. A Varian/Chemagnetics $4 \mathrm{~mm}$ double-resonance APEX HX magic-angle spinning (MAS) probe was used with a spinning rate of $10 \mathrm{kHz}$. Spectra were acquired using a 90 degree pulse width of $2.5 \mu \mathrm{s}$, a recycle delay of $4 \mathrm{~s}$, and 512 scans to achieve high signal to noise spectra. We ensured that the 4 s recycle delay was long enough for complete proton spin-lattice relaxation by measuring $\mathrm{T}_{1}$ of the $0.0 \mathrm{ppm}^{-\mathrm{OH}_{\mathrm{AP}}}$ peak to be $0.11 \mathrm{~s}$. Due to the sensitivity of ${ }^{1} \mathrm{H}$ NMR as well as the hygroscopic nature of HAP NPs, it was found necessary to have precise control over the water content of the HAP powders so that spectral deconvolution would be consistent. For example, we hypothesized (correctly) that the ${ }^{1} \mathrm{H}$ spectrum of untreated HAP would not change significantly when treated in $\mathrm{F}^{-}$-free batch tests (figure 2-d); yet, unless the samples were dried correctly the water peak, being so broad, would distort the appearance of the entire spectrum, particularly the $\mathrm{OH}^{-}$AP peak, and complicate the deconvolution of the small ${ }^{1} \mathrm{H}_{-} \mathrm{OH}^{-}{ }_{\mathrm{AP}} \cdots \mathrm{F}^{-}$AP peaks. Thus, HAP samples were placed under vacuum at $160^{\circ} \mathrm{C}$ for $12 \mathrm{~h}$, transferred to a glovebag, and packed into $4 \mathrm{~mm}$ o.d. zirconia rotors under an $\mathrm{N}_{2}$ atmosphere. Note that this heat treatment did not alter the linewidth or mass normalized intensity of the $\mathrm{OH}^{-}$AP resonance. In addition to minimizing the distortion of the ${ }^{1} \mathrm{H}$ spectrum by lowering the water resonance, we also needed to seal off the sample, once 
packed in the NMR rotor, from re-adsorbing atmospheric water. With normal rotor spacers and caps we would see this happen resulting in the appearance of peaks at $\sim 1.3 \mathrm{ppm}$ and $\sim 3.4 \mathrm{ppm}$ after a few minutes; this has been reported in the literature ${ }^{30}$. This was particularly relevant because of our goal to accurately quantify the $\mathrm{OH}^{-}{ }_{\mathrm{AP}} \cdots \mathrm{F}^{-}$AP peaks at $\delta_{\text {iso }}\left({ }^{1} \mathrm{H}\right)=1.3-1.8 \mathrm{ppm}$, which overlapped with this re-adsorbed water. Therefore, specialty double o-ring Kel-F spacers and caps were used with the rotors to ensure air-tight environments so as to prevent water intrusion. We ensured that the ${ }^{1} \mathrm{H}$ signal from the o-rings (which also coincidentally appeared in the chemical shift range of interest) was minimized by flipping the orientation of the spacer and using a single o-ring to seal both ends in the farthest possible position away from the sample (see figure S16). This seal worked to keep out moisture intrusion for at least $72 \mathrm{~h}$ (data not shown). The ${ }^{1} \mathrm{H}$ spectrum of an empty rotor with the caps on was acquired and incorporated into the deconvolutions of the HAP spectra (see figure S17).

Spectra were processed using Topspin v. 4.06 and MestReNova v.14.0.0. For all quantified spectra $\left({ }^{1} \mathrm{H}\right.$ and $\left.{ }^{19} \mathrm{~F} \mathrm{DP}\right)$, three zero-fills and no line broadening were applied to the FIDs. The baselines were corrected using a Bernstein $3^{\text {rd }}$ order polynomial fit. 


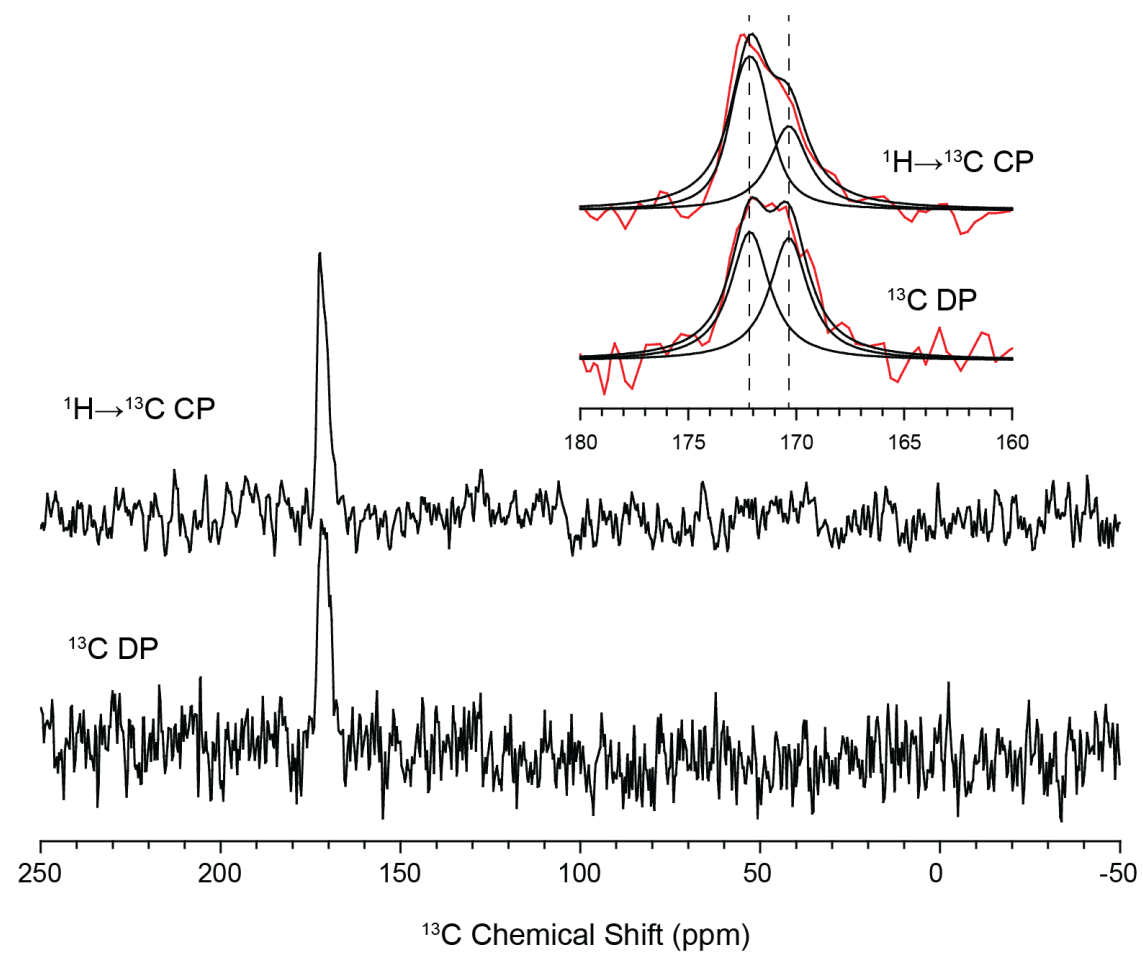

Figure S9. ${ }^{13} \mathrm{C}$ DP and CP (from ${ }^{1} \mathrm{H}$ ) MAS NMR spectra of HAP. Deconvolutions of the spectral peaks are inset with Lorentzian peaks at 170.4 and 172.2 ppm, both with linewidths of $325 \mathrm{~Hz}$.

Table S2. Peak deconvolution and quantification of ${ }^{19} \mathrm{~F}$ resonances of HAP fluoridated for various treatment times and dried at $50{ }^{\circ} \mathrm{C}$ fitted using a 50\% (Lorentzian/Gaussian) Voigt lineshape.

\begin{tabular}{|c|c|c|c|c|c|c|c|}
\hline Sample & \multicolumn{3}{|c|}{ F'cAP Resonance $^{-}$} & \multicolumn{3}{|c|}{ F $_{\text {AP Resonance }}$} & Total \\
\hline $\begin{array}{c}\text { Trtmt time } \\
{[\mathrm{h}]}\end{array}$ & $\begin{array}{l}\delta_{\text {iso }}\left\{{ }^{19} \mathrm{~F}\right\} \\
{[\mathrm{ppm}]^{+}}\end{array}$ & $\begin{array}{l}\text { FWHM } \\
{[\mathrm{kHz}]}\end{array}$ & $\begin{array}{c}{ }^{19} \mathrm{~F} \text { signal/ } \\
\text { sample mass }\end{array}$ & $\begin{array}{c}\delta_{\text {iso }}\left\{{ }^{19} \mathrm{~F}\right\} \\
{[\mathrm{ppm}]}\end{array}$ & $\begin{array}{l}\text { FWHM } \\
{[\mathrm{kHz}]}\end{array}$ & $\begin{array}{c}{ }^{19} \mathrm{~F} \text { signal/ } \\
\text { sample mass }\end{array}$ & $\begin{array}{c}\text { Capacity } \\
\text { [mg-F/g-HAP] }\end{array}$ \\
\hline 1 & $-93(1)$ & 6.5 & 0.010 & $-103.8(4)$ & 6.5 & 0.028 & $1.42(0.80)$ \\
\hline 6 & $-91.7(5)$ & 6.5 & 0.019 & $-102.8(3)$ & 6.5 & 0.056 & $2.83(0.80)$ \\
\hline 24 & $-92.0(5)$ & 6.25 & 0.034 & $-102.5(2)$ & 6.25 & 0.090 & $4.67(0.80)$ \\
\hline 144 & $-92.0(5)$ & 6.25 & 0.074 & $-102.0(2)$ & 6.25 & 0.199 & $10.29(0.80)$ \\
\hline 864 & $-91.5(4)$ & 6 & 0.107 & $-101.9(2)$ & 5.5 & 0.316 & $15.97(0.80)$ \\
\hline
\end{tabular}

${ }^{\dagger}$ The value in the parentheses refer to the uncertainty of the isotropic peak chemical shift to the last reported digit based on both the signal to noise (S/N) and the peak linewidth (FWHM); ${ }^{*}$ All ${ }^{19} \mathrm{~F}$ signals are normalized by the sample mass. The mass-normalized ${ }^{19} \mathrm{~F}$ signal of the $864 \mathrm{~h}$ sample was equated with the experimental $\mathrm{F}^{-}$uptake at $864 \mathrm{~h}$ (15.97 mg-F/g-HAP) and then normalized by the theoretical F- capacity of the untreated HAP (i.e. $37.74 \mathrm{mg}$-F/g-HAP). The $864 \mathrm{~h}$ sample, having the highest $\mathrm{S} / \mathrm{N}$, was used as the reference to the rest of the samples. In other words, the mass-normalized ${ }^{19} \mathrm{~F}$ signal of the $1-144 \mathrm{~h}$ samples were scaled in proportion to the mass-normalized ${ }^{19} \mathrm{~F}$ signal of the $864 \mathrm{~h}$ signal. The sum of the $\mathrm{F}_{\mathrm{CAP}}^{-}$and $\mathrm{F}_{\mathrm{AP}}^{-}{ }^{19} \mathrm{~F}$ signal/sample mass equates to the $\mathrm{F}^{-}$fraction. Due to the high signal to noise ratio $(\mathrm{S} / \mathrm{N})$ of the $864 \mathrm{~h}$ sample spectrum, an error of $5 \%$ was applied to the quantitation value. As the $\mathrm{S} / \mathrm{N}$ decreases for samples treated at decreasing times (see figure 2-b), we assigned the same absolute error value to each quantitation value. Thus, the error reaches up to $56 \%$ at the $1 \mathrm{~h}$ time point to compensate for the lower $\mathrm{S} / \mathrm{N}$. 


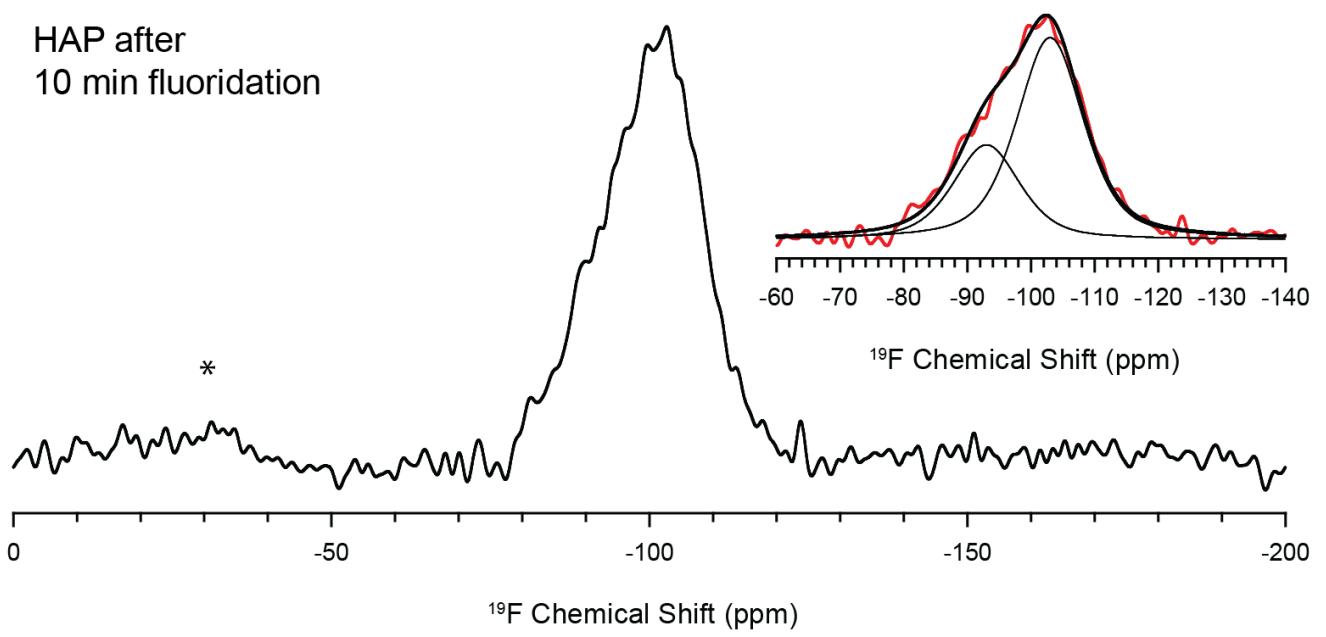

Figure S10. ${ }^{19} \mathrm{~F}$ DP NMR spectrum and deconvolution (inset) of powdered HAP fluoridated for 10 min in a completely mixed batch reactor (CMBR). The asterisk denotes a spinning side band. The chemical shifts of the $F^{-}{ }_{C A P}$ and $F^{-}{ }_{A P}$ peaks were $-93.0 \pm 1.0 \mathrm{ppm}$ and $-103.1 \pm 0.3 \mathrm{ppm}$, respectively. Both peaks were fit with a linewidth of $\mathrm{FWHM}=7 \mathrm{kHz}$. The powder was sieved between 32-124 $\mu \mathrm{m}$ mesh sizes. Approximately $1.00 \mathrm{~g}$ of powder was added to $1 \mathrm{~L}$ of magnetically-stirred (at high speed) water with the same initial conditions as the $30 \mathrm{mg}-\mathrm{F} / \mathrm{L}$ DCBR tests. After $10 \mathrm{~min}$ of mixing, the powder was removed from the water using a Büchner funnel lined with filter paper, and dried at $50{ }^{\circ} \mathrm{C}$. A sample was also taken for measurement of $\mathrm{F}^{-}$concentration. The aliquot was filtered using a Pall Acrodisc(C) $0.2 \mu \mathrm{m}$ ion chromatography filter prior to the concentration measurement. Approximately $2.23 \pm 0.08 \mathrm{mg}-\mathrm{F} / \mathrm{g}-\mathrm{HAP}$ was removed by this point, about the same amount removed after $2 \mathrm{~h}$ in the DCBR test. The much smaller mass transfer barrier by intrapellet pores of the powder explains the significantly faster initial uptake kinetics.

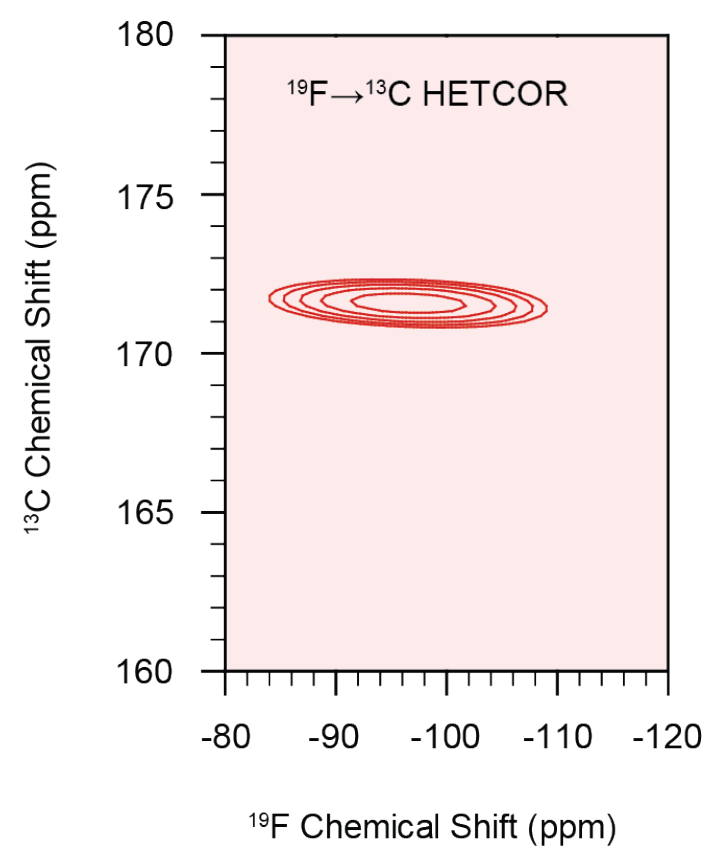

Figure S11. ${ }^{19} \mathrm{~F} \rightarrow{ }^{13} \mathrm{C}$ HETCOR spectrum of HAP fluoridated for $864 \mathrm{~h}$. 


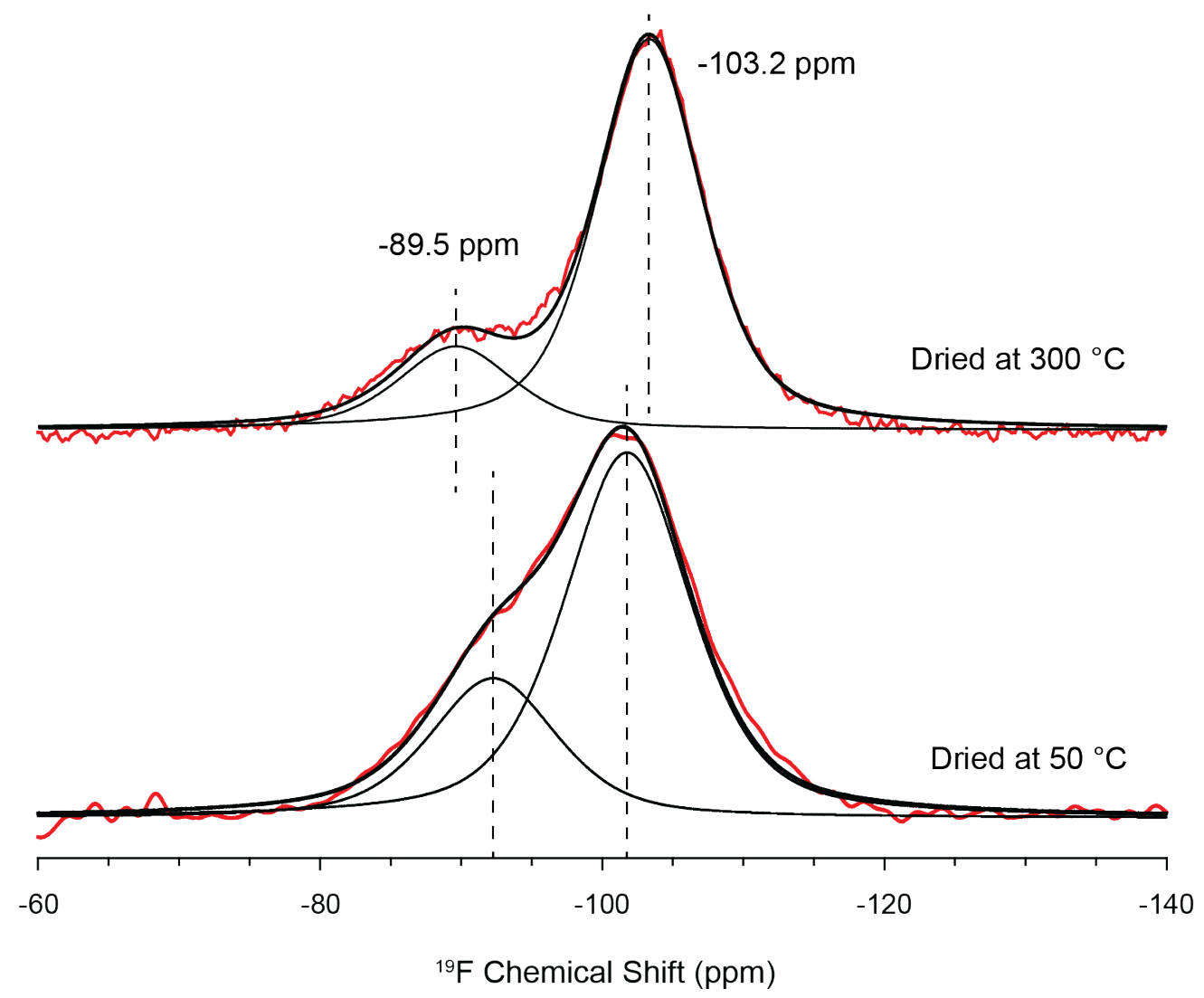

Figure S12. ${ }^{19} \mathrm{~F}$ DP spectra and deconvolutions (MAS at $40 \mathrm{kHz}$ spin speed using the Multiacquisition sequence described previously) of fluoridated $\mathrm{AP}\left(144 \mathrm{~h}\right.$ of treatment) dried at $50{ }^{\circ} \mathrm{C}$, and spectra of subsequent heat treatment at $300{ }^{\circ} \mathrm{C}$ for $12 \mathrm{~h}$. Heat treatment causes the two resonances to split further apart and narrow in linewidth (FWHM) as $\mathrm{F}^{-}$ions in the apatite settle into more thermodynamically stable, less disordered crystallographic positions. Resonances of the sample dried at $50{ }^{\circ} \mathrm{C}$ were deconvoluted into two $6.25 \mathrm{kHz}$ FWHM peaks (see table S2), whereas heat treatment at $300{ }^{\circ} \mathrm{C}$ reduces the $\mathrm{F}^{-}{ }_{\mathrm{AP}}$ resonance $\mathrm{FWHM}$ to $5 \mathrm{kHz}$ and the $\mathrm{F}^{-} \mathrm{CAP}$ resonance to $5.5 \mathrm{kHz}$. 


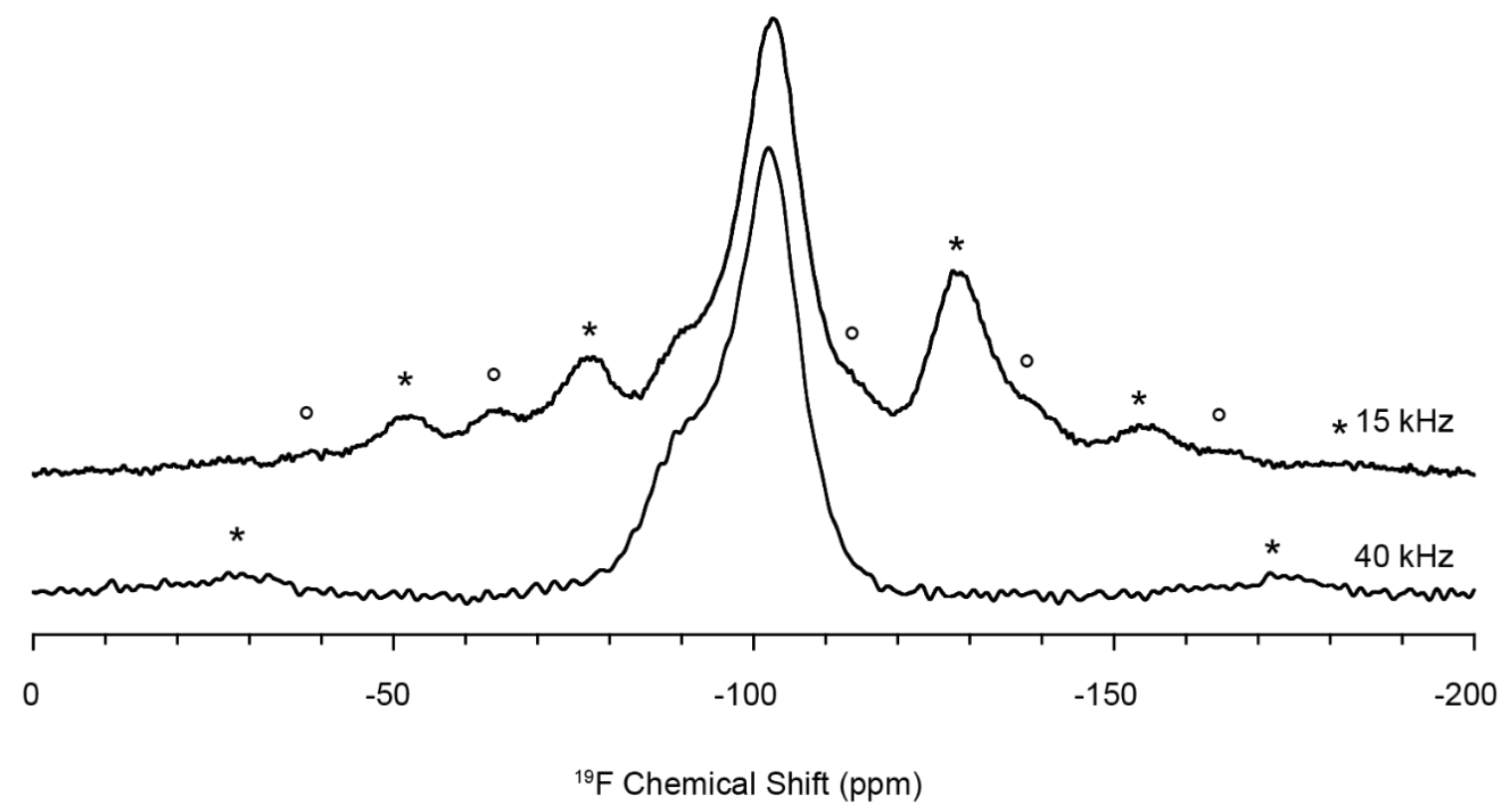

Figure S13. ${ }^{19} \mathrm{~F}$ DP MAS NMR spectra of AP fluoridated at $864 \mathrm{~h}$ at $15 \mathrm{kHz}$ and $40 \mathrm{kHz}$ spinning speeds. Asterisks and circles denote spinning sidebands of $\mathrm{F}^{-}{ }_{\mathrm{AP}}$ and $\mathrm{F}^{-}{ }_{\mathrm{CAP}}$ resonances, respectively.

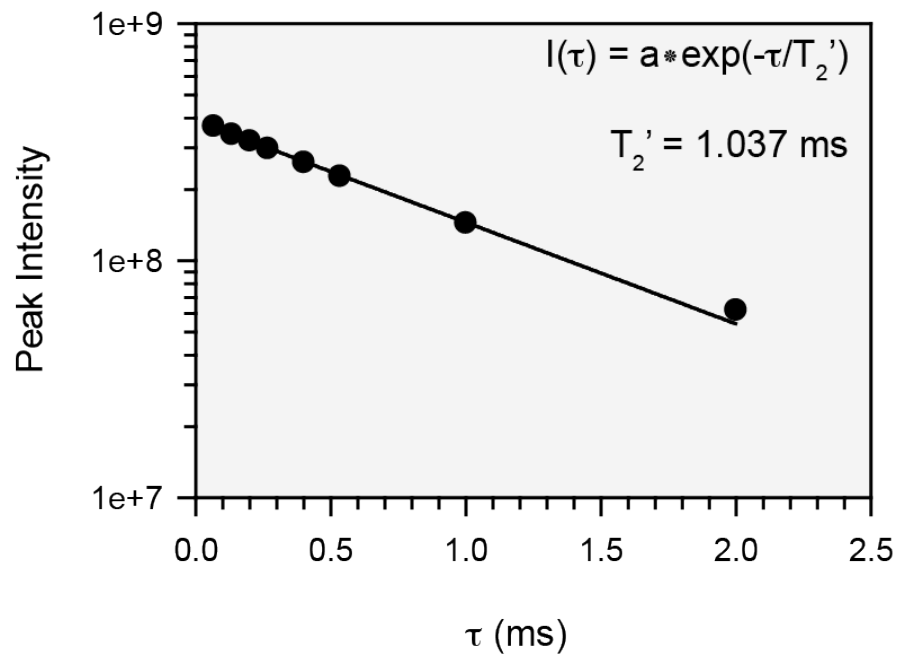

Figure S14. The transverse relaxation decay of $\mathrm{F}_{\text {AP }}^{-}$peak at $\delta_{\text {iso }}\left({ }^{19} \mathrm{~F}\right)=-102 \mathrm{ppm}$ in AP fluoridated for $144 \mathrm{hrs}$. 


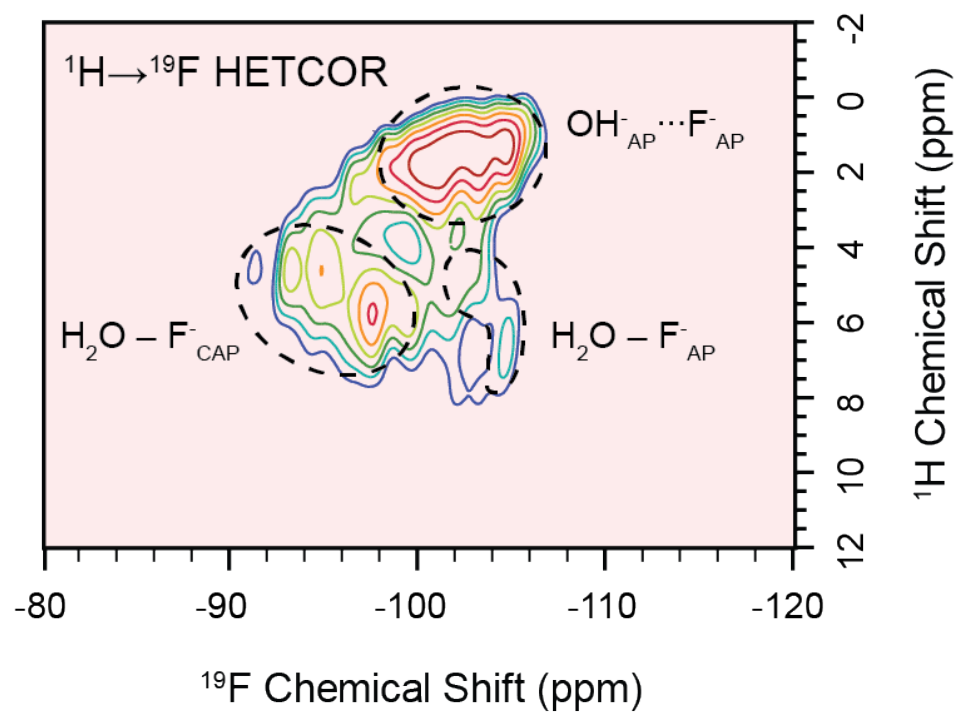

Figure S15. ${ }^{1} \mathrm{H} \rightarrow{ }^{19} \mathrm{~F}$ HETCOR NMR spectrum of AP after $864 \mathrm{~h}$ of fluoridation at $15 \mathrm{kHz}$ spinning speed. The poor signal to noise of the ${ }^{1} \mathrm{H} \rightarrow{ }^{19} \mathrm{~F}$ (nuclei with both high sensitivity and natural abundance) HETCOR spectrum, even as the experiment took $\sim 41 \mathrm{~h}$ to complete, can be partially explained by low number of $\mathrm{F}^{-}{ }_{(\mathrm{C}) \mathrm{AP}}$ to $\mathrm{OH}^{-}{ }_{\mathrm{AP}} / \mathrm{H}_{2} \mathrm{O}$ interactions in the $\mathrm{X}$ channel. Regions outlined by dashed lines indicate connectivity between distinct ${ }^{19} \mathrm{~F}$ and ${ }^{1} \mathrm{H}$ species, as labeled in the figure. The $\mathrm{OH}^{-}{ }_{\mathrm{AP}} \cdots \mathrm{F}^{-}{ }_{\mathrm{AP}}$ hydrogen bond region is discussed in the main text, though it should be noted here that increased ${ }^{1} \mathrm{H}$ chemical shift (which indicates a stronger hydrogen bond) correlates with increased ${ }^{19} \mathrm{~F}$ chemical shift in this region, and that the ${ }^{1} \mathrm{H}$ linewidths increase with increased ${ }^{19} \mathrm{~F}$ shift. According to work by Yesinowski and Eckert ${ }^{31}$, we decided to deconvolute the ${ }^{1} \mathrm{H}$ DP spectra using three peaks at $\delta_{\text {iso }}\left({ }^{1} \mathrm{H}\right)=1.3,1.5$, and $1.8 \mathrm{ppm}$. This is reflected in the ${ }^{1} \mathrm{H}$ spectra deconvolutions in figure S17 and table S3. The second and third regions in the ${ }^{1} \mathrm{H} \rightarrow{ }^{19} \mathrm{~F}$ HETCOR spectrum includes correlation resonances of $\mathrm{F}_{\text {CAP }}^{-}$at $\delta_{\text {iso }}\left({ }^{19} \mathrm{~F}\right)=-91.4$ to $-99.3 \mathrm{ppm}$ with $\delta_{\text {iso }}\left({ }^{1} \mathrm{H}\right)=4.5$ to $5.8 \mathrm{ppm}$ as well as $\mathrm{F}^{-}$AP at $\delta_{\text {iso }}\left({ }^{19} \mathrm{~F}\right)=-102.2$ to $-104.7 \mathrm{ppm}$ with $\delta_{\text {iso }}\left({ }^{1} \mathrm{H}\right)=4.9$ to $6.7 \mathrm{ppm}$, respectively. The major water peak of AP is broad and centers around $\delta_{\text {iso }}\left({ }^{1} \mathrm{H}\right)=5-6 \mathrm{ppm}^{30-32}$, making it likely that each ${ }^{1} \mathrm{H}$ correlation resonance in these regions denote water molecules in distinct moieties. The opposite trend is observed in these regions compared with the first where higher ${ }^{19} \mathrm{~F}$ chemical shifts correlate with lower ${ }^{1} \mathrm{H}$ chemical shifts. If we follow the example of the $\mathrm{OH}^{-}$AP to $\mathrm{F}^{-}$AP hydrogen bond rule, then a higher ${ }^{1} \mathrm{H}$ chemical shift in $\mathrm{H}_{2} \mathrm{O}$ resonances indicate stronger hydrogen bonds; but, the reason for the opposite effect on the ${ }^{19} \mathrm{~F}$ chemical shift is unclear. It is noteworthy that the $\mathrm{F}_{\text {CAP }}^{-}$correlation resonance appears to drop significantly at $\delta_{\text {iso }}\left({ }^{19} \mathrm{~F}\right) \approx-93 \mathrm{ppm}$, whereas the $\mathrm{F}_{\text {CAP }}^{-}$isotropic peak maximum is at $-91.5 \mathrm{ppm}$, suggesting that nearby water molecules play a significant role in decreasing the chemical shift of $\mathrm{F}_{\text {CAP }}^{-}$from that in high crystallinity carbonated FAPs. This would be entirely consistent with Ivanova et al. ${ }^{24}$ where they determined structural water in carbonated AP to be located in both $\mathrm{X}^{-}$channels and near $\mathrm{B}$ type $\mathrm{CO}_{3}{ }^{2-}$ defects, precisely where $\mathrm{F}^{-}{ }_{\mathrm{AP}}$ and $\mathrm{F}^{-} \mathrm{CAP}$ are expected to be, respectively. We have no evidence to support whether the water resonances in the ${ }^{1} \mathrm{H} \rightarrow{ }^{19} \mathrm{~F}$ HETCOR correlations can be attributed to surface water, structural water, or a mixture of both. If some or all are surface water molecules, then it likely indicates $\mathrm{F}^{-}(\mathrm{C}) \mathrm{AP}$ at surface lattice sites in close proximity with water molecules in the ACP layer. 


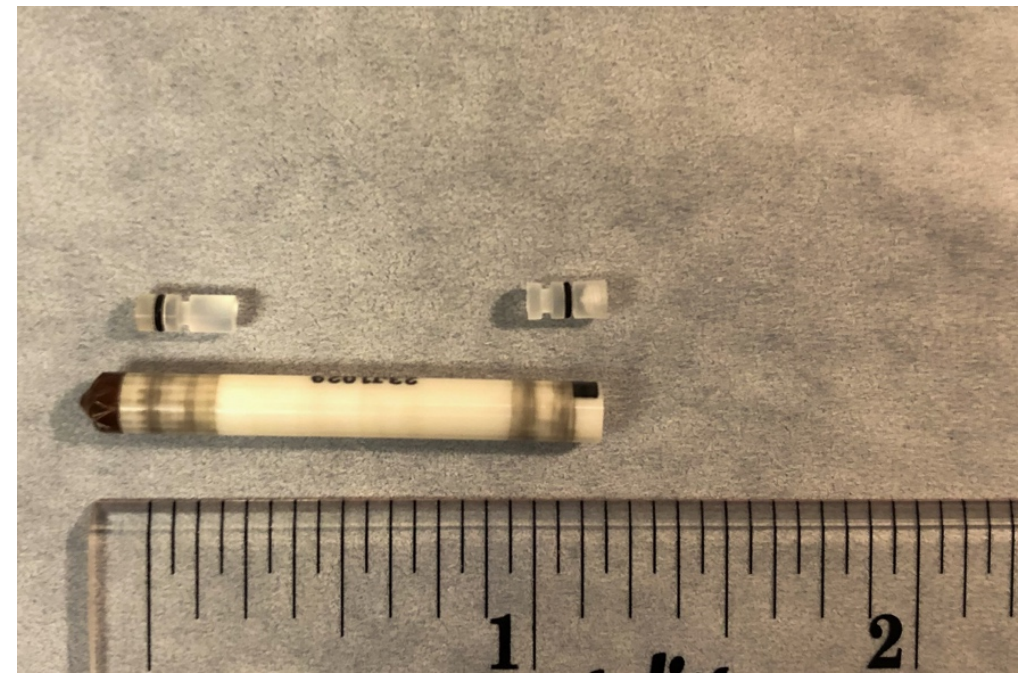

Figure S16. Configuration of $4 \mathrm{~mm}$ zirconia rotor used for acquisition of ${ }^{1} \mathrm{H}$ DP (quantitative) NMR spectra with special o-ring caps positioned with o-rings farthest away from the sample as possible. Ruler units are in inches. 

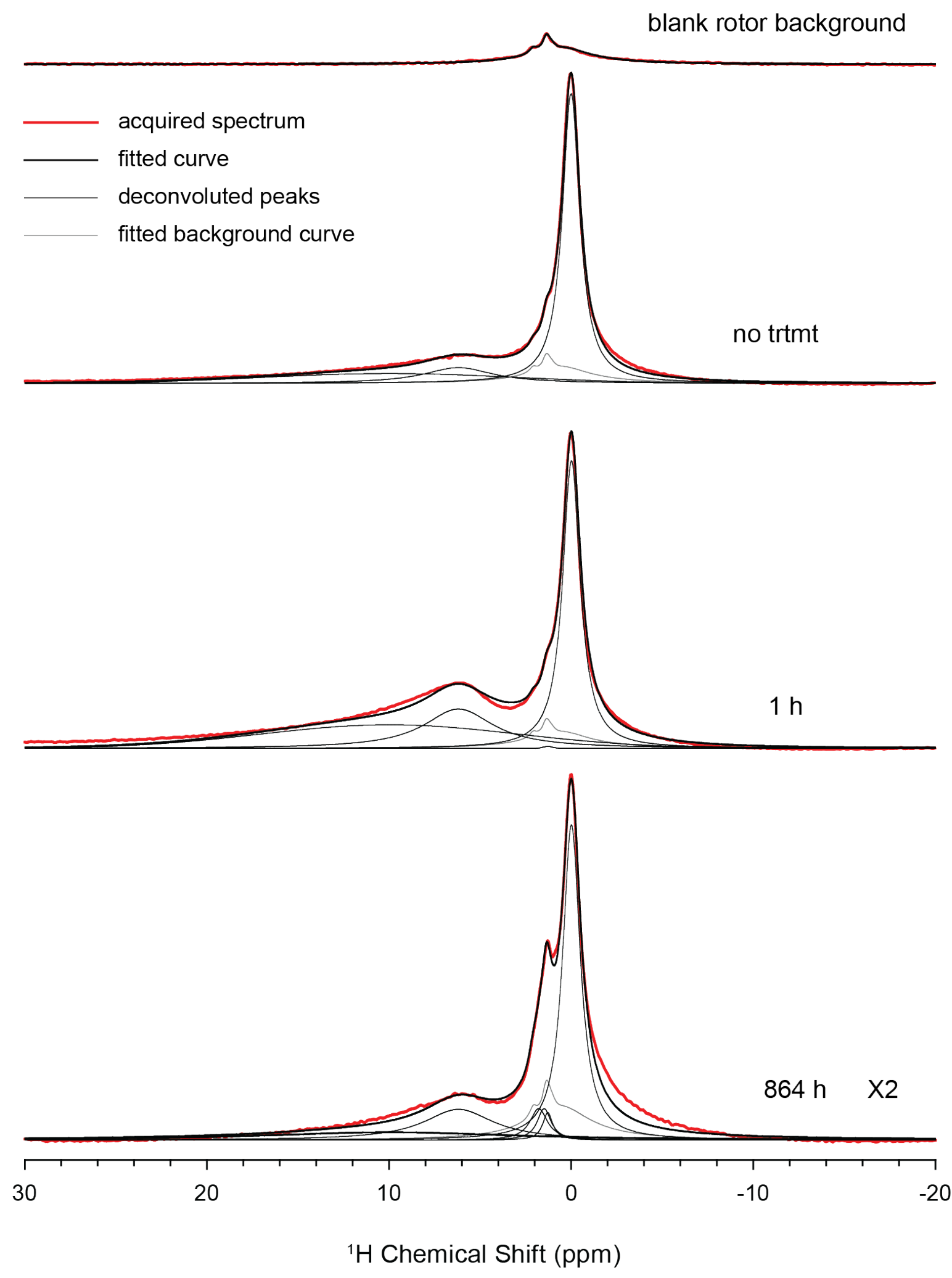
Figure S17. At the top is a spectrum acquired from an empty rotor with the o-ring caps in place where a small but significant set of resonances is apparent. This spectrum was fitted and that fitted curve was included into the deconvolutions of the spectra of HAP samples in order to negate the contribution of the background peak to $\mathrm{OH}^{-}$AP quantification. It is responsible for the small shoulder peaks to the left of the $0.0 \mathrm{ppm}$ peak in the untreated and $\mathrm{F}^{-}$-free samples. Beneath the background spectrum are ${ }^{1} \mathrm{H}$ DP MAS NMR spectra and their deconvolutions of untreated HAP and HAP fluoridated for $1 \mathrm{~h}$ and $864 \mathrm{~h}$. Four peaks represent $\mathrm{OH}^{-}$AP species: free $\mathrm{OH}^{-}{ }_{\mathrm{AP}}$ at $\delta_{\text {iso }}\left({ }^{1} \mathrm{H}\right)=0.0 \mathrm{ppm}(\mathrm{FWHM}=350 \mathrm{~Hz})$ and three types of $\mathrm{OH}^{-}{ }_{\mathrm{AP}}$ hydrogen bonded to $\mathrm{F}^{-}{ }_{\mathrm{AP}}$ (deduced according to the ${ }^{1} \mathrm{H} \rightarrow{ }^{19} \mathrm{~F} \mathrm{HETCOR}$ spectrum in figure S15) at $\delta_{\text {iso }}\left({ }^{1} \mathrm{H}\right)=1.3 \mathrm{ppm}$ (FWHM $=200 \mathrm{~Hz}), \delta_{\text {iso }}\left({ }^{1} \mathrm{H}\right)=1.5 \mathrm{ppm}(\mathrm{FWHM}=275 \mathrm{~Hz})$, and $\delta_{\text {iso }}\left({ }^{1} \mathrm{H}\right)=1.8 \mathrm{ppm}(\mathrm{FWHM}=350 \mathrm{~Hz})^{16,31}$. Additionally, the best fit curves included a broad $\mathrm{H}_{2} \mathrm{O}$ peak located at $\delta_{\text {iso }}\left({ }^{1} \mathrm{H}\right)=6.2 \mathrm{ppm}(\mathrm{FWHM}$ $=1400 \mathrm{~Hz}$ ) as well as a peak at $\delta_{\text {iso }}\left({ }^{1} \mathrm{H}\right)=10.0 \mathrm{ppm}$ with $\mathrm{FWHM}=5000 \mathrm{~Hz}$ typically assigned to $\mathrm{HPO}^{2-}$ as exemplified in Jäger et al. ${ }^{33}$. All peaks are fitted using a Lorentzian lineshape except for the HPO42- peak, fitted to a Gaussian lineshape. The same chemical shifts, linewidths, and lineshapes are used to fit each spectra from figure 2 for the $\mathrm{OH}^{-}$AP quantification produced in figure 1 of the main text, with more detail in table S3 below.

Table S3. Quantification of the $\mathrm{OH}^{-}$AP contribution to ${ }^{1} \mathrm{H}$ resonances of untreated $\mathrm{HAP}, \mathrm{F}^{-}$-free treated HAP for $144 \mathrm{~h}$, and HAP fluoridated for various treatment times and dried at $160{ }^{\circ} \mathrm{C}$. The linewidths and lineshapes are specified in the caption of figure S17.

\begin{tabular}{|c|c|c|c|c|c|}
\hline Sample & $\begin{array}{c}\delta\left({ }^{1} \mathrm{H}\right)= \\
0.0 \mathrm{ppm}\end{array}$ & $\begin{array}{c}\delta\left({ }^{1} \mathrm{H}\right)= \\
1.3 \mathrm{ppm}\end{array}$ & $\begin{array}{c}\delta\left({ }^{1} \mathrm{H}\right)= \\
1.5 \mathrm{ppm}\end{array}$ & $\begin{array}{c}\delta\left({ }^{1} \mathrm{H}\right)= \\
1.8 \mathrm{ppm}\end{array}$ & Total \\
\hline $\begin{array}{c}\text { Treatment } \\
\text { time }[\mathrm{h}]\end{array}$ & $\begin{array}{c}{ }^{1} \mathrm{H} \text { signal/ } \\
\text { sample } \\
\text { mass }^{+}\end{array}$ & $\begin{array}{c}{ }^{1} \mathrm{H} \text { signal/ } \\
\text { sample mass }\end{array}$ & $\begin{array}{c}{ }^{1} \mathrm{H} \text { signal/ } \\
\text { sample mass }\end{array}$ & $\begin{array}{c}{ }^{1} \mathrm{H} \text { signal/ } \\
\text { sample mass }{ }^{\dagger}\end{array}$ & $\begin{array}{c}\text { Equiv. } \\
\text { Exchange } \\
{[\mathrm{mg}-\mathrm{F} / \mathrm{g}-\mathrm{HAP}]^{*}}\end{array}$ \\
\hline none & 1.023 & - & - & - & - \\
\hline 144 (no F) & 0.977 & - & - & - & - \\
\hline 1 & 0.914 & 0.002 & 0.000 & 0.000 & $1.86(0.09)$ \\
\hline 6 & 0.841 & 0.030 & 0.000 & 0.000 & $2.85(0.14)$ \\
\hline 24 & 0.743 & 0.049 & 0.006 & 0.008 & $4.32(0.22)$ \\
\hline 144 & 0.618 & 0.071 & 0.006 & 0.040 & $5.91(0.30)$ \\
\hline 864 & 0.473 & 0.024 & 0.037 & 0.047 & $9.33(0.47)$ \\
\hline
\end{tabular}

${ }^{\dagger}$ All ${ }^{1} \mathrm{H}$ signals were normalized by the sample mass. These normalized signals were then scaled to the averaged signals of the untreated HAP and F-free treated HAP for $144 \mathrm{~h}$, which acted as the reference material. Adding up each $\mathrm{OH}^{-}{ }_{\mathrm{AP}}$ chemical shift species in a sample leads to its total $\mathrm{OH}_{\mathrm{AP}}^{-}$quantity relative to 1 . *Using the known composition and unit cell parameters of $\mathrm{F}^{-}$-free HAP we calculated the amount of $\mathrm{OH}_{\mathrm{AP}}^{-}$lost at each treatment time. The difference between the reference and given sample ${ }^{1} \mathrm{H}$ signal quantities represents the $\mathrm{OH}_{\mathrm{AP}}^{-}$lost from that sample due to fluoridation. For instance, the sum of $\mathrm{OH}^{-}{ }_{\mathrm{AP}}$ signal after $864 \mathrm{~h}$ is 0.581 , so the percent of $\mathrm{OH}_{\mathrm{AP}}^{-}$lost is $(1-0.581)^{*} 100=41.9 \%$. If it is assumed that it is replaced by $\mathrm{F}^{-}(\mathrm{C}) \mathrm{AP}$ this deficit could be converted to an equivalent $\mathrm{F}^{-}$ exchange amount. The standard deviation of the signals for the two reference samples is $3.3 \%$, a fairly standard error for quantitative $\mathrm{NMR}^{34}$. Given the high $\mathrm{S} / \mathrm{N}$ of all our ${ }^{1} \mathrm{H} \mathrm{DP}$ spectra, we therefore assigned a conservative $5 \%$ error to all samples. 

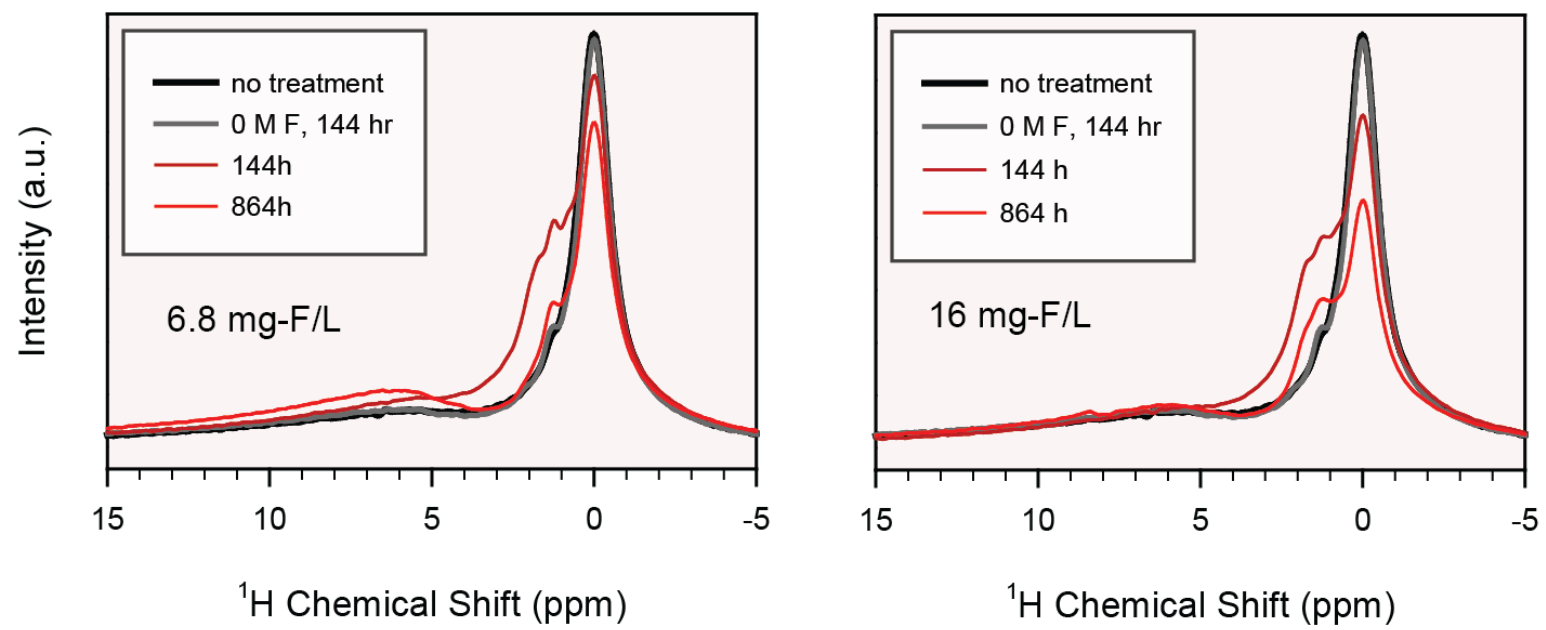

Figure S18. ${ }^{1} \mathrm{H}$ DP MAS NMR of HAP treated in DCBR tests with initial $\mathrm{F}^{-}$concentrations of 6.8 $\mathrm{mg} / \mathrm{L}$ (left) and $16 \mathrm{mg} / \mathrm{L}$ (right) for 144 and $864 \mathrm{~h}$. These spectra are plotted alongside untreated HAP and HAP treated with $\mathrm{F}^{-}$-free water for $144 \mathrm{~h}$, just as in figure $2-\mathrm{c}, \mathrm{d}$ in the main text. All spectra are mass normalized.

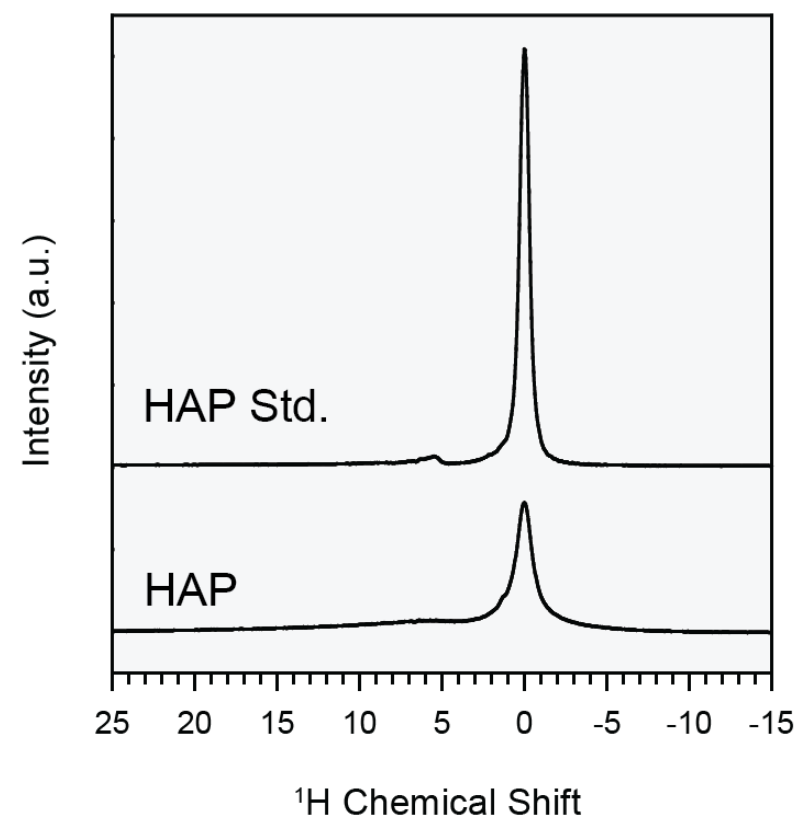

Figure S19. ${ }^{1} \mathrm{H}$ DP MAS NMR of untreated HAP and a HAP standard (same as in the XRD and FTIR analysis in figures S4-5). The spectra were obtained using the same acquisition parameters as the quantitative ${ }^{1} \mathrm{H}$ NMR spectra in figure S17. The same rotor background was subtracted for the deconvolution of the $\mathrm{OH}^{-}$AP peak at $0.0 \mathrm{ppm}$. The HAP standard peak was fitted using a Lorentzian curve and had a linewidth of $200 \mathrm{~Hz}$, indicative of its high crystallinity. 


\section{Transmission Electron Microscopy}

A JEOL $2010 \mathrm{LaB}_{6}$ TEM, operated at $200 \mathrm{kV}$, was used for conventional imaging of AP NPs (see figure S20-a for example) at the MRL-UIUC. High resolution TEM was conducted using a JEOL 2200FS TEM at the Australian Centre for Microscopy and Microanalysis at the University of Sydney, also operated at 200 kV. Example images are shown in figure S20-b-e. Prior to analysis, $\sim 0.01 \mathrm{mg}$ of HAP powder was sonicated in $1 \mathrm{~mL}$ of ethanol for 15 minutes. A drop of the suspension was pipetted onto a holey-carbon 200 mesh copper TEM grid (Ted Pella Inc.) and air-dried.

Particles were observed under beam intensities of less than $40 \mathrm{pA} / \mathrm{cm}^{2}$ and images were acquired within two minutes. Particle size distributions (PSDs) of the AP variants were measured using low magnification (40kx) images so that many particles could be measured without sacrificing resolution. We considered measurable particles as being clearly rod or ellipsoidal in shape. It was too time consuming to find lone particles in sufficient numbers, so the dimensions of particles in small agglomerates were also measured. Because the orientation of the agglomerate particles were not verified, it is likely that the measured length of a significant fraction of particles is somewhat lower than their true length dimension. This effect is exemplified by the rod-shape particle in figure S18-d - it is oriented along the [111] zone axis with respect to the electron beam; its actual particle length (parallel to [001]) is $\sim 36^{\circ}$ off axis, resulting in a perceived length $\sim 19 \%$ smaller than its true length. For every measurable particle, both its length and diameter were measured. These dimensions are easy to discern for HAP whose hexagonal crystal symmetry (space group: Hexagonal $P 6 / 3 m$ ) characteristically leads to particles exhibiting an anisotropic rod-like shape. To minimize bias, all particles were measured 
using images of the same magnification at randomly selected areas of the TEM grid. Generally, anywhere from 25 to 65 particles were measured per image. Once the total number of particles measured exceeded $n=600$, no more images were selected; although the rest of the measurable particles in the final image were measured to prevent bias. Thus, anywhere from 600 to 650 particles were measured per sample. Images were processed using ImageJ.

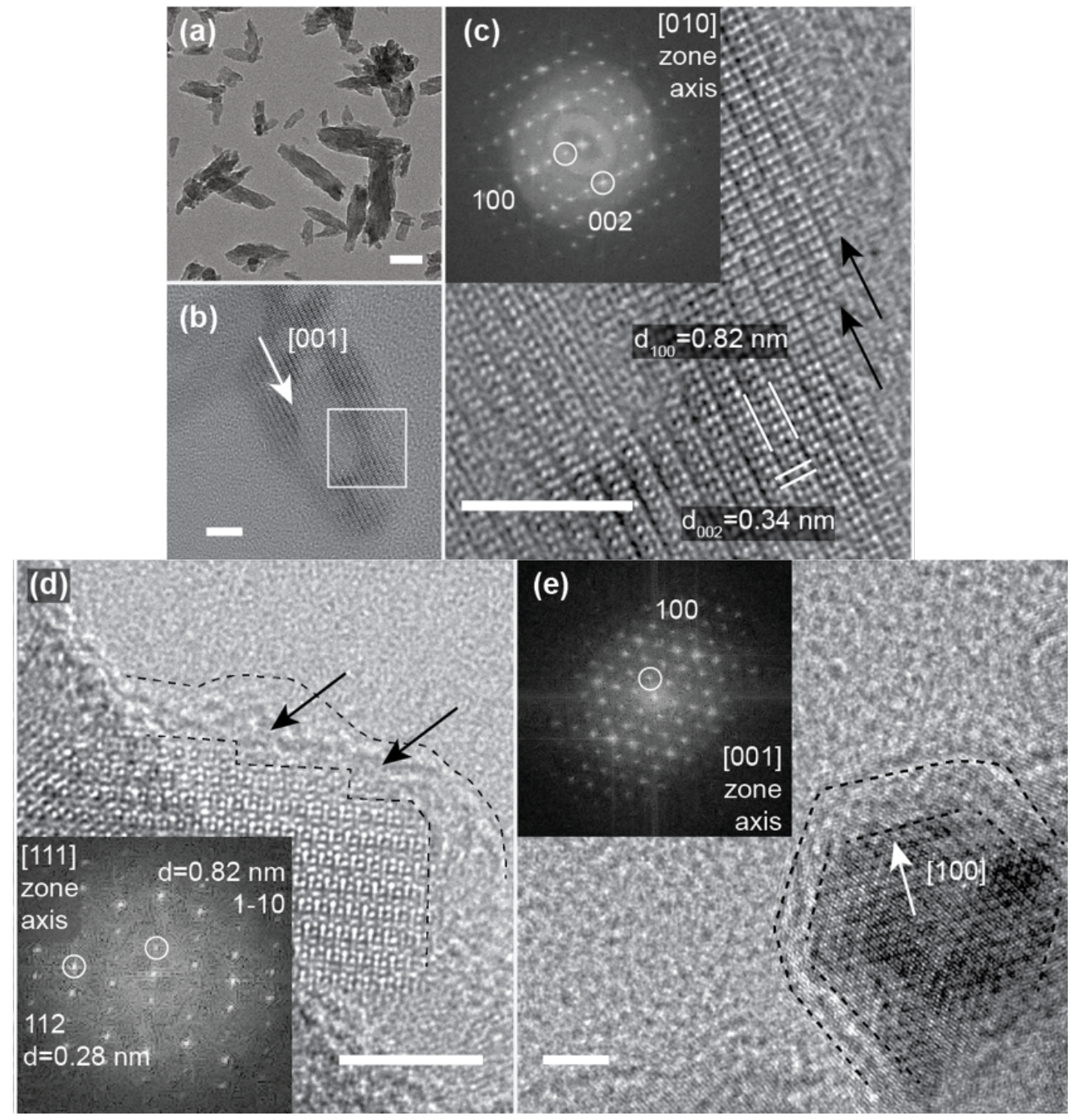

Figure S20. (a) TEM image of untreated HAP NPs. Scale bar is set to $50 \mathrm{~nm}$. (b-e) High resolution brightfield TEM images of AP NPs and smaller features after $864 \mathrm{~h}$ fluoridation. Scale bars are 5 $\mathrm{nm}$. The particle in (b-c) was the only one observed among $\sim 50$ without an amorphous surface. Image (c) is the expanded area outlined by the white box in (b). Insets in (c-e) are Fast Fourier transforms of the crystal areas. Surface steps can be seen at $\{010\}$ surfaces of AP NPs denoted by black arrows. Amorphous surfaces are denoted by dashed lines in (d-e). 
Specific Surface Area $\left(\mathrm{m}^{2} / \mathrm{g}\right)$

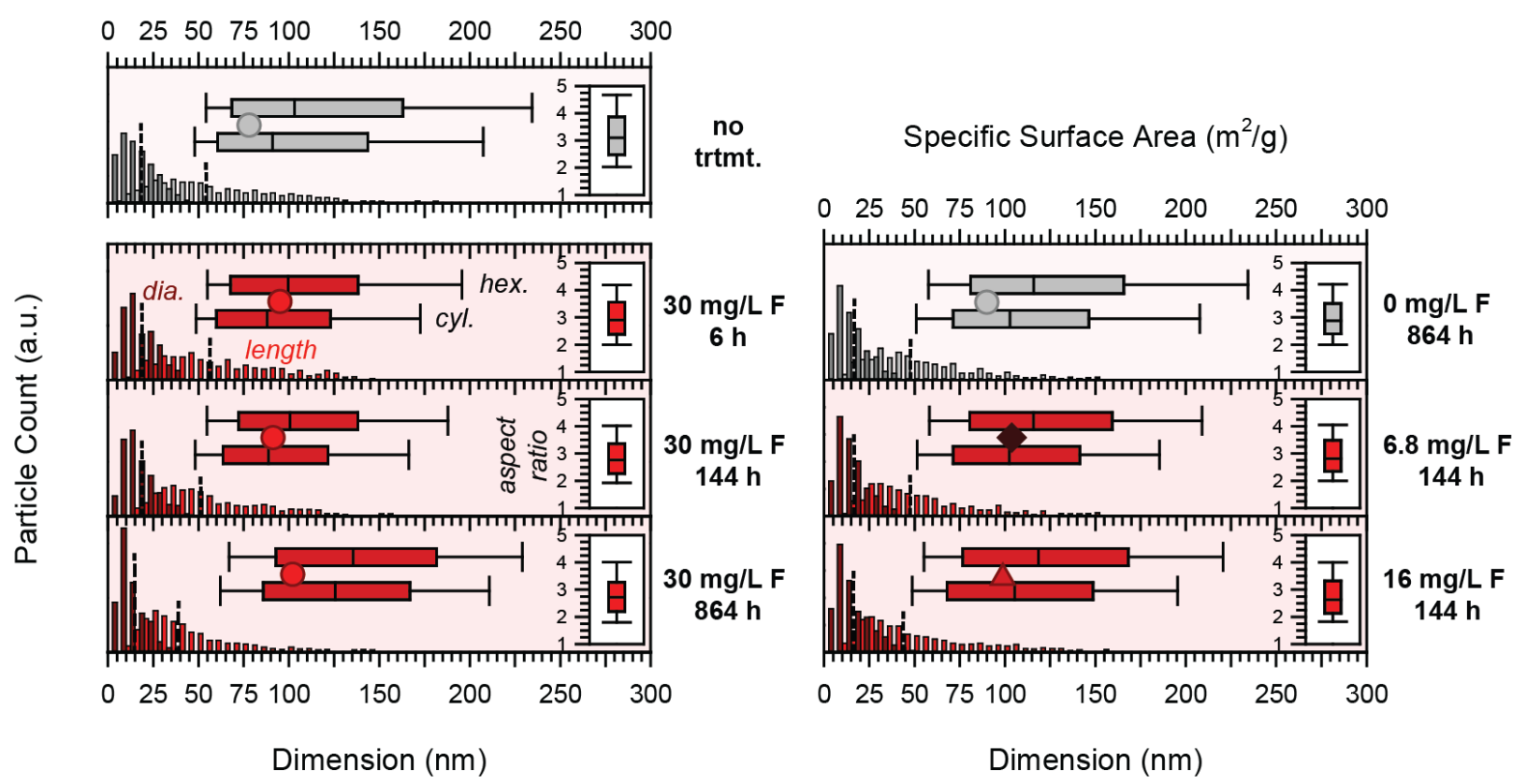

Figure S21. Histogram PSDs of HAP before treatment and at different treatment times (concentrations and treatment time noted at the right-hand-side of each plot) with and without $\mathrm{F}^{-}(\mathrm{n}=600-650)$. Values were binned into $5 \mathrm{~nm}$ segments by rounding down. For instance, the number of particles having a length $15 \leq l<20$ is binned into the $15 \mathrm{~nm}$ length. To distinguish length and diameter bars they are plotted right and left, respectively, of their corresponding tick mark, and the diameter bars are darker in color. The median diameter and length for each sample (calculated prior to binning) is plotted as a vertical black dashed line. The horizontal box and whisker plots represent SSA calculated using particle dimensions, with scenarios for both cylindrical (lower) and hexagonal prism (upper) morphologies. The average BET SSAs are placed alongside for comparison. The horizontal scale for the PSDs and the SSAs are the same. Inset right are box and whisker plots of NP aspect ratio. The whiskers correspond to $10^{\text {th }}$ and $90^{\text {th }}$ percentiles. 


\section{SECTION S4. METHODOLOGY TO CALCULATE SSA, ADSORPTION, AND TOTAL X SITES}

\section{Crystal Structure and Density}

HAP as well as FAP take on the hexagonal $P 6_{3} / m$ space group ${ }^{35}$. In this crystallographic space group, $a=b$ with angle $\gamma=120^{\circ}$ and an orthogonal $c$-axis (scheme S2), the density of the unit cell is calculated as:

$$
\rho_{H A P}=\frac{\text { unit cell atomic mass }}{\sin \left(\frac{\pi}{3}\right) a^{2} c}
$$

where the unit cell atomic mass is the mass of calcium (9.01), phosphate (4.92), carbonate (1.08), and hydroxide (1.10) ions per unit cell. We also included water (1.35/unit cell) based on research suggesting that B-type carbonate impurities over a broad wt. \% contribution creates space for a fairly constant amount of water incorporated structurally into the apatite ${ }^{19}$. The denominator is the unit cell volume of HAP using cell parameters acquired via the whole pattern fitting refinement of the X-ray diffractograms from figure S4-b.

Scheme S2. HAP/FAP stoichiometric unit cell denoted by purple dashed lines. Calcium ions are blue, while grey tetrahedrons with red spheres at the vertices are phosphate ions. $\mathrm{Ca}(\mathrm{II})$ ions are distinguished by their bonds with the green spheres. Green spheres are $\mathrm{OH}^{-} / \mathrm{F}^{-}$ions; their position reflects the $\mathrm{F}_{\mathrm{AP}}^{-}$position in the $\mathrm{c}$-axis oriented $\mathrm{X}^{-}$channel with fractional coordinates $(0.0,0.0,0.25)$, which lies in the plane of the $\mathrm{Ca}(\mathrm{II})$ triangle. $\mathrm{OH}_{\mathrm{AP}}^{-}$ions by comparison are situated slightly above or below the $\mathrm{Ca}(\mathrm{II})$ triangle plane.

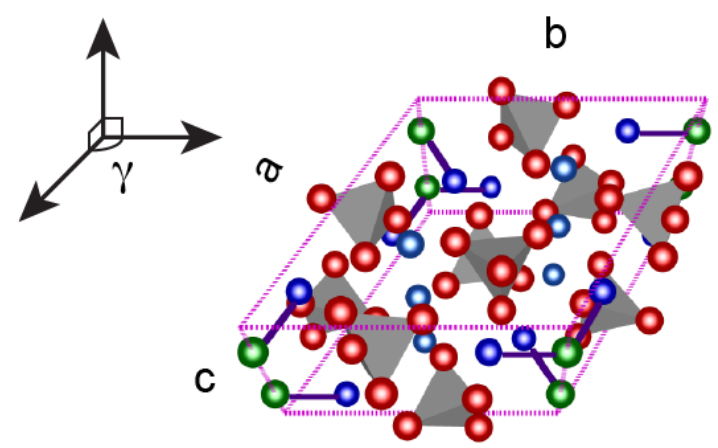


A unit conversion results in $\rho_{H A P}=2.945 \mathrm{~g} / \mathrm{cm}^{3}$ for the untreated sample. By contrast, the density of a stoichiometric HAP using the PDF \#04-007-2837 unit cell parameters is $3.159 \mathrm{~g} / \mathrm{cm}^{3}$, consistent with the literature ${ }^{36}$. The lower value for our material reflects the difference in composition due to $\mathrm{CO}_{3}{ }^{2-}$ for $\mathrm{PO}_{4}{ }^{3-}$ substitutions and concomitant $\mathrm{Ca}^{2+}$ and $\mathrm{OH}^{-}$vacancies.

In parallel we needed to consider the mass contribution from the ACP surface layer. This is noteworthy because experimental $\mathrm{F}^{-}$uptake capacity is calculated as the mass of $\mathrm{F}^{-}$removed from solution divided by the initial mass of bulk HAP. Accordingly, to provide consistency in our model calculations the number of both adsorption and bulk sites per particle are divided by the mass of the entire particle, where the particle mass is calculated by the product of density and particle volume (V); this includes the mass contribution from the ACP layer. ACP is known to be significantly less dense than HAP ${ }^{37}$. ACP density was calculated from its known "unit" stoichiometry $\left(\mathrm{Ca}_{9}\left(\mathrm{PO}_{4}\right)_{6}\right)$ along with its unit particle size $(1.2 \mathrm{~nm} \text { diameter average })^{6}$. Furthermore, ACP contains $10-20 \%$ water by weight ${ }^{38}$. Using the baseline particle model scenario, we estimated that 10 water molecules per ACP unit (16\% water by weight) would give our global material (HAP + ACP) a total of $6.8 \mathrm{wt}$. \% water, which is on par with our TGA measurement ( 8.1 wt. \% water).

$$
\rho_{A C P}=\frac{A C P \text { unit atomic mass }}{\frac{4}{3} \pi r^{3}}
$$

This results in a reasonable value of $\rho_{A C P}=2.038 \mathrm{~g} / \mathrm{cm}^{3}$.

Hence, our calculations of particle mass incorporated this aspect:

$$
\text { total particle mass }=\rho V=\rho_{H A P} V_{c C}+\rho_{A C P} V_{A C P}
$$


where $V_{c c}$ is the volume of the HAP crystal core and $V_{A C P}$ is the volume of the ACP surface (equivalent to $\mathrm{V}-\mathrm{V}_{\mathrm{cc}}$ ).

\section{ACP Thickness Distribution}

We approximated the ACP surface thickness $(\mathrm{t})$ initially as $1 \mathrm{~nm}$ in the first box plot of figure 3 (left) of the main text simply to compare the results between cylindrical and hexagonal prism morphologies as well as stepped bipyramidal hexagonal prism habit/morphology. After the hexagonal prism model was chosen (both for its high adsorption capacity estimate as well as computational ease), we applied a more rigorous definition of t to the particle model. Knowing that a distribution of $t$ exists across and within particles based on our TEM work, we applied three different lognormal probability distribution functions to t (figure S22-a). The first (mean $\mu=0.1$ and standard deviation $\sigma_{t}=0.25$ ) was meant to cover the low-end of the thicknesses observed, while the third $\left(\mu=0.6, \sigma_{t}=0.25\right)$ was to cover the high-end of thicknesses observed. Finally, the one we chose to represent our adsorption capacity estimates $\left(\mu=0.25, \sigma_{t}=0.5\right)$ was due to its breadth across all of the ACP thicknesses observed (0-5 nm), while 60\% of thicknesses had a probability of being in between 1-2 $\mathrm{nm}$ (see cumulative distribution functions in figure S22-b). Each particle was randomly assigned a thickness according to probability, and the cumulative distribution of those random assignments are depicted in figure S22-b, showing a good match with the original functions. In addition, we set a minimum cutoff thickness of 0.75 $\mathrm{nm}$ where if a particle was assigned a t value below $0.75 \mathrm{~nm}$ it was reset to $0 \mathrm{~nm}$, as is clear in the cumulative distributions. There is a physical reason for this, which is that the 'unit' size for ACP particles is as mentioned $1.2 \mathrm{~nm}$ in diameter, and has been observed to be as small as 0.95 $\mathrm{nm}^{38}$. It is therefore likely that any smaller dimension is simply not feasible to be stable, and we 
chose the cutoff to be conservative in the case that attachment to the AP crystal core can stabilize ACP somewhat. For the probability distribution functions defined by $\mu=0.1 / \sigma_{t}=0.25$ and $\mu=0.25 / \sigma_{t}=0.5$, around $8 \%$ and $16 \%$, respectively, of all particles are assigned to have an ACP thickness of $0 \mathrm{~nm}$. This results in shifting the adsorption capacity distributions higher than they would be without this correction.

(a)

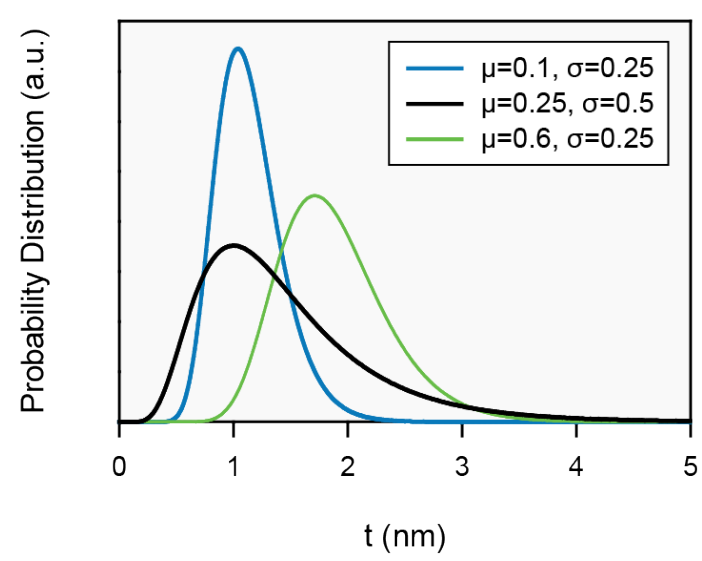

(b)

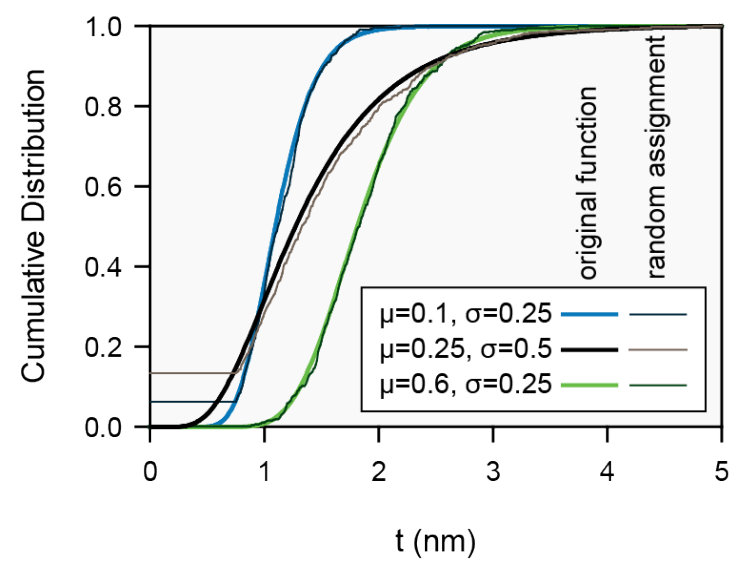

Figure S22. (a) Probability distributions and their corresponding (b) cumulative distributions used for $t$.

\section{Cylinder and Hexagonal Prism Morphologies}

HAP particles are rod shaped and can be approximated as a cylinder, hexagonal prism, or bipyramidal hexagonal prism with length (I, $[\mathrm{nm}])$ and diameter $(\mathrm{d},[\mathrm{nm}])$ as depicted in scheme S3. Calculations for the bipyramidal hexagonal prism receive separate treatment in the next section.

To calculate SSA of a particle, we first needed measurements of its dimensions gathered from a TEM image. 
Scheme S3. Abstraction of HAP NP from a TEM image.
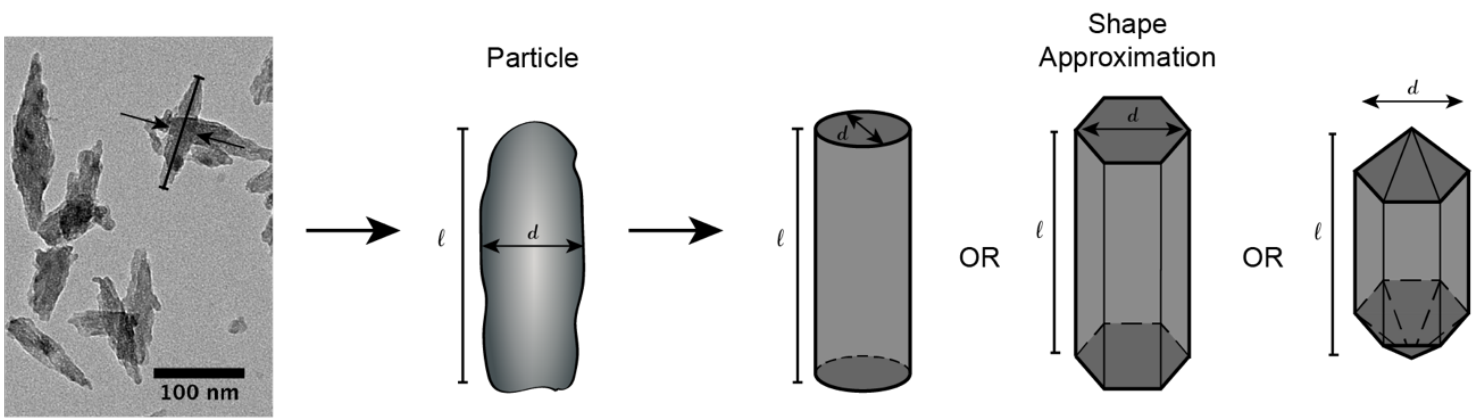

For a cylindrical geometry:

$$
\begin{gathered}
\text { Surface Area: } S A=\frac{1}{2} \pi d^{2}+\pi d l \\
\text { Volume: } V=\frac{1}{4} \pi d^{2} l \\
\text { Specific Surface Area: } S S A=S A / \rho V
\end{gathered}
$$

For a hexagonal prism geometry:

$$
\begin{gathered}
\text { Surface Area: } S A=3 \sqrt{3}\left(\frac{d}{2}\right)^{2}+6\left(\frac{d}{2}\right) l \\
\text { Volume: } V=\frac{3 \sqrt{3}}{2}\left(\frac{d}{2}\right)^{2} l \\
\text { Specific Surface Area: } S S A=S A / \rho V
\end{gathered}
$$

To calculate the surface and bulk quantities of AP lattice sites, we must relate the raw particle dimensions with the dimensions of the crystal core (see scheme S4). We assumed that an amorphous calcium phosphate (non-apatitic) surface layer covered the entire particle with a thickness, $t$, verified by HRTEM images of HAP particles (figure S20-d,e). Therefore, the diameter dimension that represents the crystal core $\left(d_{c c}\right)$ is simply the measured particle diameter subtracted by the amorphous surface layer thickness; the same goes for the particle length: 


$$
\begin{gathered}
d_{c c}=d-2 t \\
l_{c c}=l-2 t
\end{gathered}
$$

Scheme S4. Determining crystal core dimensions from cylindrical and hexagonal prism morphology.

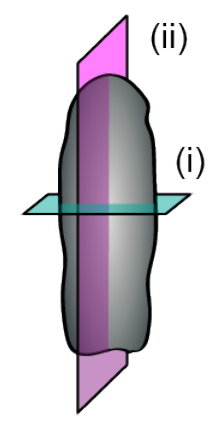

(i)
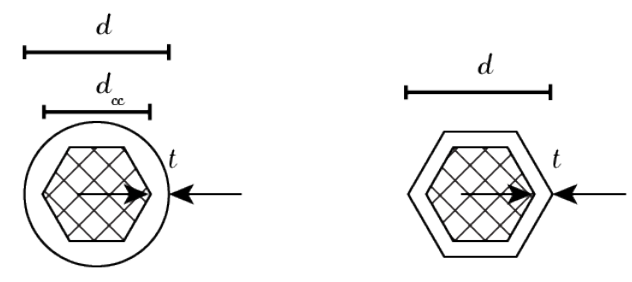

(ii)

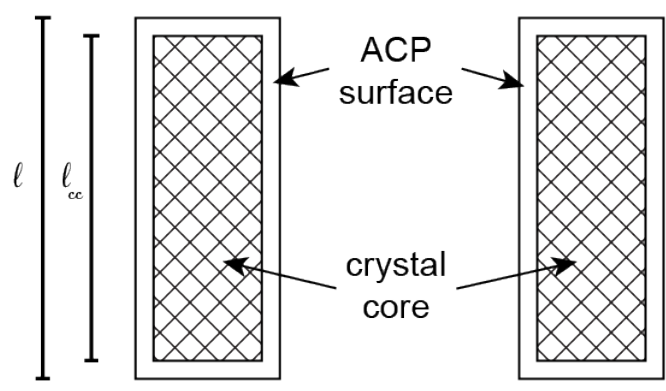

Using HRTEM images (figure S20-b-e), we approximate the underlying geometry of the HAP crystal core to be a hexagonal prism with and without steps at the rod caps, assuming that the major surface planes include the $\{001\}$ family (at rod caps) and $\{010\}$ family (along the length of the rod), as they are consistently computed to be the two most stable surfaces ${ }^{39-41}$. We used the corresponding $\mathrm{X}_{\mathrm{AP}}^{-}$surface concentrations of 1 site per (001) (ab) unit cell face and 2 sites per (010) (ac) unit cell face, which amounts to $\sigma_{\mathrm{ab}}=1.31 \mathrm{sites} / \mathrm{nm}^{2}$ and $\sigma_{\mathrm{ac}}=3.08 \mathrm{sites} / \mathrm{nm}^{2}$, respectively, using the unit cell dimensions for untreated HAP from XRD. Similarly, the $1 D X_{A P}^{-}$ concentrations along an [010] (a) edge and an [001] (c) edge are 1 site/a dimension and 2 sites/c dimension, respectively.

Using these assumptions, we can calculate the quantity of surface sites of each particle using the crystal core length $\left(I_{c c}\right)$ and diameter $\left(d_{c c}\right)$, the unit cell dimensions ( $a$ and $\left.c\right)$, surface site 
densities ( $\sigma_{a b}$ and $\left.\sigma_{a c}\right)$, and amorphous surface layer thickness $(t)$. Below we split these calculations into four distinct entities to separate planar sites from edge sites, as depicted in scheme S5.

1. $a b$ planar sites ( 2 hexagonal faces): $\quad 3 \sqrt{3}\left[\frac{1}{2}\left(d_{c c}-2 a\right)\right]^{2} * \sigma_{a b}$

2. $a$ edge sites (12 edges):

$$
12\left(\frac{1}{2} d_{c c}-a\right) * \frac{1}{a}
$$

3. ac planar sites (6 rectangular faces): $\quad 6\left(\frac{1}{2} d_{c c}-2 a\right)\left(l_{c c}-c\right) * \sigma_{a c}$
4. $c$ edge sites (6 edges):
$6\left(l_{c c}-c\right) * \frac{2}{c}$

Note that the reason for subtracting unit cell dimensions from the crystal core dimensions is to avoid the double counting of edge and vertex sites. The reason that edge sites were calculated separately from planar sites is so that they could be easily adapted when considering edge defects modulating $\{010\}$ surface $X$ occupancy.

Scheme S5. Delineation of different surface sites.

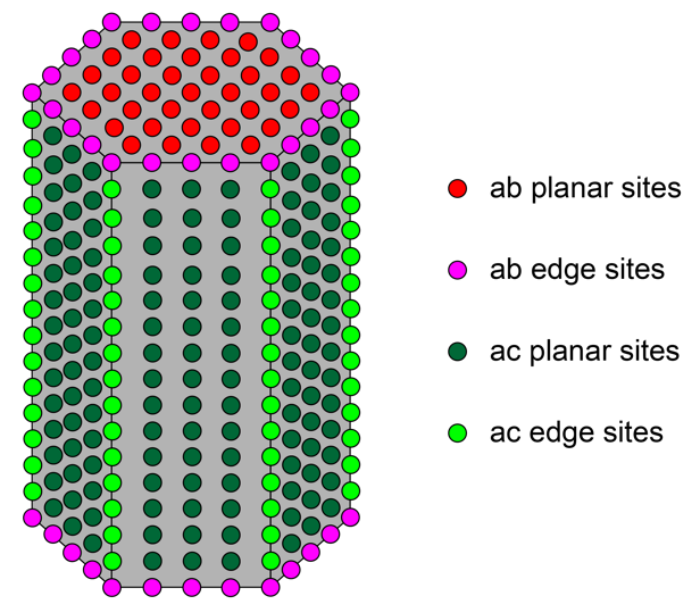

Calculation of the specific surface site (SSS) concentration (this quantity is what is used in the main text, referred to as adsorption capacity) requires that we normalize the number of surface sites of each particle by its total mass. 


$$
\text { SSS }=\left(\frac{X^{-} \text {occupancy }}{2}\right)\left(\frac{\text { sum of surface sites }}{\rho V N_{A}}\right) \quad\left[\frac{\text { moles of } X^{-}}{g H A P}\right]
$$

where $N_{A}$ is Avogadro's number. The $X$ occupancy term acknowledges that when calculating the surface $X$ concentration at faces and edges, we use the stoichiometric amount of $2 X$ ions per unit cell. In the final specific surface site quantity, the actual occupancy is determined from the untreated HAP composition, of $1.86 \mathrm{X}$ ions per unit cell, if all calcium ions were utilized. Recall that the $\mathrm{OH}_{\text {AP }}^{-}$occupancy of the untreated material is actually $1.1 \mathrm{OH}^{-}$per unit cell according to our composition analysis, but that there is extra calcium in the stoichiometry that could be used to charge balance extra $\mathrm{F}^{-}$. Therefore, to be conservative we use the highest $\mathrm{X}$ occupancy that our material could possibly handle to maximize the adsorption capacity estimation. A unit conversion brings the final value to $\mathrm{mg}-\mathrm{F} / \mathrm{g}-\mathrm{HAP}$.

The specific total $X$ site concentration (STS), the number of total $X$ sites per unit mass of particle) is a simpler calculation. The number of $X^{-}$per particle is twice the ratio between the crystal core volume to one unit cell volume, because there are two $X-$ per unit cell. The concentration is the number of $X^{-}$in the particle divided by the molar mass of the particle. The $X$ - occupancy is again factored in.

$$
\text { STS }=\left(2 X^{-} \text {sites }\right)\left(\frac{X^{-} \text {occupancy }}{2}\right)\left(\frac{\frac{3 \sqrt{3}}{2}\left(\frac{d_{c c}}{2}\right)^{2} l_{c c}}{a^{2} c * \sin \left(\frac{\pi}{3}\right)}\right)\left(\frac{1}{\rho V N_{A}}\right) \quad\left[\frac{\text { moles of } O H^{-}}{g H A P}\right]
$$

In both cylindrical and hexagonal prism particle morphology, the crystal core takes on the same hexagonal prism habit, so its volume is the same in either case; however, the volume of the particle itself is distinct.

Quantifying X sites of subsurface or internal layers is a simple extension of the surface site calculations, where the length and diameter parameters (for isotropic internalization) are 
smaller by two unit cell dimensions for each iteration of internal layers. As a consequence, the number of $X$ sites decreases with progressively internal isotropic layers. On the other hand, anisotropic internalization along [001] is the addition of $a b$ surface site layers.

\section{Bipyramidal Hexagonal Prism Morphology}

To determine the adsorption sites and bulk sites for particles modeled with bipyramidal hexagonal prism morphologies, the calculations are more involved. The first task was to generate a general definition of the hexagonal prism geometry based on HAP crystal structure parameters (scheme S6). In this, we assumed that the middle portion of the rod length is flat along [001] and that crystal steps begin somewhere when approaching the rod caps. For simplicity the steps are uniform in each particle in that the prism slope $\left(r_{s}\right.$, step height to depth ratio) is linear and leads to an apex with as little (001) surface as possible, thus resulting in a pyramidal cap rather than a truncated pyramidal or parabolic cap. The step height was defined as an integer multiple of the [001] unit cell dimension, $c(0.689 \mathrm{~nm})$, and the step depth an integer multiple of the [010] unit cell dimension, $a(0.940 \mathrm{~nm})$. Generally speaking, this prism slope should be $>1$ because the particles' aspect ratios are $>1$ and the elongated ellipsoidal morphology of some particles gives that appearance. On the other hand, the prism slope shouldn't be too large or there would be steps along the entire length of the particles and make the particle diameter smaller than that measured. To account for aspect ratio distribution, $r_{\mathrm{s}}$ would be scaled according to the aspect ratio by the following classification:

$$
r_{\mathrm{s}}= \begin{cases}\frac{3 c}{a}, & \text { aspect ratio }-1>\frac{3 c}{a} \\ \frac{2 c}{a}, & \frac{3 c}{a}>\text { aspect ratio }-1>\frac{2 c}{a} \\ \frac{c}{a}, & \text { aspect ratio }-1<\frac{2 c}{a}\end{cases}
$$


The step depth in the [010] direction was typically observed to be a single unit cell length, $a$. Accordingly, the number of steps, s, in a particle is determined by the expression

$$
s=\frac{\left(d_{c c} / 2\right)}{a}
$$

The length of the straight side of the hexagonal prism, $l_{s}$, is then a function of both $r_{s}$ and $s$.

$$
l_{s}=l_{c c}-2 r_{s} a s
$$

To determine the number of adsorption sites, the calculation can be split between the hexagonal prism and the two stepped pyramidal caps. For the hexagonal prism section, the three quantities are sites at the $a c$ plane and $c$ and $a$ edges.
1. $a$ edge sites (12 edges):
$12\left(\frac{1}{2} d_{c c}-a\right) * \frac{1}{a}$
2. ac planar sites (6 rectangular faces):
$6\left(\frac{1}{2} d_{c c}-2 a\right)\left(l_{c c}-c\right) * \sigma_{a c}$
3. $c$ edge sites ( 6 edges):
$6\left(l_{c c}-c\right) * \frac{2}{c}$

For the pyramidal steps, the adsorption sites are calculated by a single expression formed by a summation of the sites at each individual step.
4. ac steps

$$
2 * 6\left(2 r_{s} \frac{a}{c}\right) \sum_{i=1}^{s-1}\left[\frac{1}{2}\left(d_{c c}-2 i a\right) * \frac{1}{a}-1\right]
$$

The factor before the expression acknowledges that there are two pyramids of six faces each; the second part calculates the number of sites in a single column on the (010) (ac) face of each step, which is a function of the step height. Because the step depth is always $a$, there are no (001) (ab) faces, just (010) faces. Of course, there are many [010] (a) and [001] (c) edges on the crystal steps, but in this case they were all lumped together into the ac face. The summation portion acknowledges that the length of each step becomes shorter moving towards the apex of the particle cap. 
Scheme S6. Determining crystal core dimensions and step surface sites from stepped bipyramidal hexagonal prism morphology.
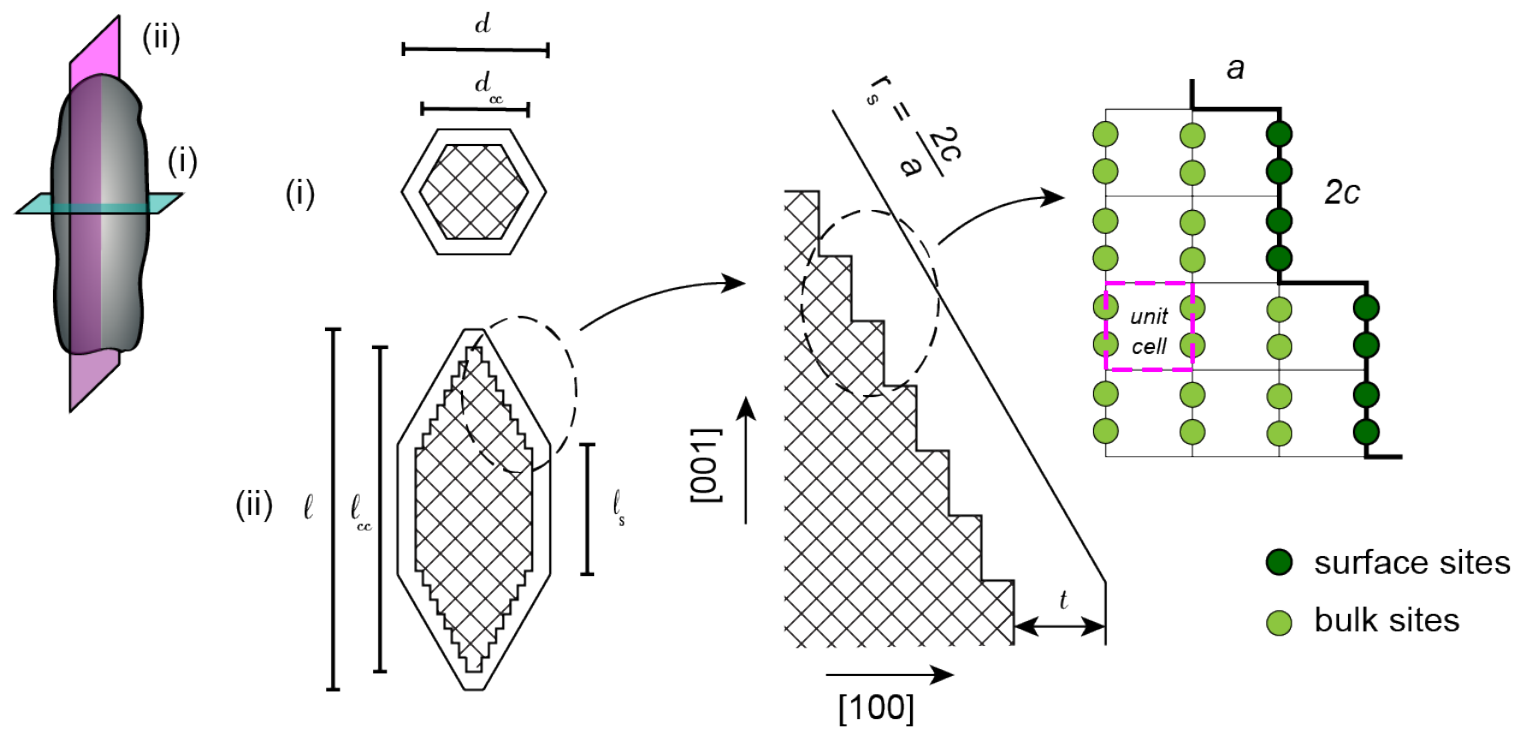

The crystal core and particle volume calculations also work by splitting up the particle into hexagonal prism and hexagonal pyramid components. Accordingly,

$$
V=\frac{2 \sqrt{3}}{2}\left(\frac{d}{2}\right)^{2} * \frac{1}{2}\left(l-l_{s}\right)+\frac{3 \sqrt{3}}{2}\left(\frac{d}{2}\right)^{2}\left(l_{s}\right)
$$

where the first component is the volume of the two pyramidal caps and the second component is the volume of the prism. Therefore,

$$
S S S=\left(\frac{X^{-} \text {occupancy }}{2}\right)\left(\frac{\text { sum of surface sites }}{\rho V N_{A}}\right) \quad\left[\frac{\text { moles of } X^{-}}{g H A P}\right]
$$

The volume of the crystal core is very similar to the volume of the particle, replacing $d$ and I with $d_{c c}$ and $I_{c c}$, respectively. As a result, the STS is

$$
\text { STS }=\left(X^{-} \text {occupancy }\right)\left(\frac{\frac{\sqrt{3}}{2}\left(\frac{d_{c c}}{2}\right)^{2}\left(l_{c c}-l_{s}\right)+\frac{3 \sqrt{3}}{2}\left(\frac{d_{c c}}{2}\right)^{2}\left(l_{s}\right)}{a^{2} c * \sin \left(\frac{\pi}{3}\right)}\right)\left(\frac{1}{\rho V N_{A}}\right)
$$




\section{REFERENCES}

1. Mosiman, D. S. The effects of various aqueous environmental conditions on the removal of fluoride in fixed bed column reactors packed with calcium hydroxyapatite pellets. University of Illinois at Urbana-Champaign, Urbana, IL, 2015.

2. Standard methods for the examination of water and wastewater. 22nd ed.; American Public Health Association: Washington D.C., 2012.

3. Benjamin, M. M., Water Chemistry. Waveland Press, Inc.: Long Grove, IL, 2002.

4. Perrone, J.; Fourest, B.; Giffaut, E., Suface characterization of synthetic and mineral carbonate fluoroapatites. Journal of Colloid and Interface Science 2002, 249, 441-452.

5. Tung, M. S.; Eidelman, N.; Sieck, B.; Brown, W. E., Octacalcium Phosphate Solubility Product from 4 to 37 C. Journal of Research of the National Bureau of Standards 1988, 93 (5), 613-624.

6. Habraken, W. J.; Tao, J.; Brylka, L. J.; Friedrich, H.; Bertinetti, L.; Schenk, A. S.; Verch, A.; Dmitrovic, V.; Bomans, P. H.; Frederik, P. M.; Laven, J.; van der Schoot, P.; Aichmayer, B.; de With, G.; DeYoreo, J. J.; Sommerdijk, N. A., Ion-association complexes unite classical and non-classical theories for the biomimetic nucleation of calcium phosphate. Nature Communications 2013, 4, 1507.

7. Moreno, E. C.; Brown, W. E.; Osborn, G., Solubility of Dicalcium Phosphate Dihydrate in Aqueous Systems. Soil Society of America Journal 1960, 24 (2), 94-98. 
8. Zhu, Y.; Zhang, X.; Chen, Y.; Xie, Q.; Lan, J.; Qian, M.; He, N., A comparitive study on the dissolution and solubility of hydroxylapatite and fluorapatite at $25 \mathrm{C}$ and $45 \mathrm{C}$. Chemical Geology 2009, 268 (1), 89-96.

9. Mason, H. E.; Kozlowski, A.; Phillips, B. L., Solid-State NMR Study of the Role of H and $\mathrm{Na}$ in AB-Type Carbonate Hydroxylapatite. Chemistry of Materials 2008, 20, 294-302.

10. Ren, F.; Ding, Y.; Leng, Y., Infrared spectroscopic characterization of carbonated apatite: A combined experimental and computational study. Journal of Biomedical Materials Research A 2014, $102 A$ (2), 496-505.

11. Fleet, M., Carbonated Hydroxyapatite: materials, synthesis, and applications. Pan Stanford Publishing: Boca Raton, FL, 2015.

12. Silvester, L.; Lamonier, J.-F.; Vannier, R.-N.; Lamonier, C.; Capron, M.; Mamede, A.-S.; Pourpoint, F.; Gervasini, A.; Dumeignil, F., Structural, textural, and acid-base properties of carbonate-containing hydroxyapatites. Journal of Materials Chemistry A 2014, 2, 1107311090.

13. McElderry, J. D. P.; Zhu, P.; Mroue, K. H.; Xu, J.; Pavan, B.; Fang, M.; Zhao, G.; McNerny, E.; Kohn, D. H.; Franceschi, R. T.; Holl, M. M. B.; Tecklenburg, M. M. J.; Ramamoorthy, A.; Morris, M. D., Crystallinity and compositional changes in carbonated apatites: Evidence from 31P solid-state NMR, Raman, and AFM analysis. Journal of Solid State Chemistry 2013, 206, 192-198.

14. LeGeros, R. Z.; Trautz, O. R.; Klein, E.; LeGeros, J. P., Two types of carbonate substitution in the apatite structure. Experientia 1969, 25 (1), 5-7. 
15. Beshah, K.; Rey, C.; Glimcher, M. J.; Schimizu, M.; Griffin, R. G., Solid state carbon13 and proton NMR studies of carbonate-containing calcium phosphates and enamel. Journal of Solid State Chemistry 1990, 84 (1), 71-81.

16. Babonneau, F.; Bonhomme, C.; Hayakawa, S.; Osaka, A., Solid State NMR Characterization of Nano-Crystalline Hydroxy-Carbonate Apatite using 1H-31P-13C Triple Resonance Experiments. Materials Research Society Symposium Proceedings 2007, 984.

17. Bertinetti, L.; Tampieri, A.; Landi, E.; Ducati, C.; Midgley, P. A.; Coluccia, S.; Martra, G., Surface Structure, Hydration, and Cationic Sites of Nanohydroxyapatite: UHR-TEM, IR, and Microgravimetric Studies. Journal of Physical Chemistry C 2007, 111, 4027-4035.

18. Markovic, M.; Fowler, B. O.; Tung, M. S., Preparation and Comprehensive Characterization of a Calcium Hydroxyapatite Reference Materials. Journal of Research of the National Institute of Standards and Technology 2004, 109, 553-568.

19. Pasteris, J. D.; Yoder, C. H.; Wopenka, B., Molecular water in nominally unhydrated carbonated hydroxylapatite: The key to a better understanding of bone mineral. American Mineralogist 2014, 99, 16-27.

20. Sudarsanan, K.; Mackie, P. E.; Young, R. A., Comparison of synthetic and mineral fluorapatite, Ca5(PO4)3F, in crystallographic detail. Materials Research Bulletin 1972, 7 (11), $1331-1337$.

21. LeGeros, R. Z.; Bonel, G.; Legros, R., Types of “H2O” in Human Enamel and in Precipitated Apatites. Calcified Tissue Research 1978, 26, 111-118. 
22. Yoder, C. H.; Pasteris, J. D.; Worcester, K. N.; Schermerhorn, D. V.; Sternlieb, M.; Goldenberg, J.; Wilt, Z., Dehydration and Rehydration of Carbonated Fluor- and Hydroxylapatite. Minerals 2012, 2, 100-117.

23. Goldenberg, J. E.; Wilt, Z.; Schermerhorn, D. V.; Pasteris, J. D.; Yoder, C. H., Structural effects on incorporated water in carbonated apatites. American Mineralogist 2015, $100,274-280$.

24. Ivanova, T. I.; Frank-Kamenetskaya, O. V .; Kol’tsov, A. B.; Ugolkov, V. L., Crystal Structure of Calcium-Deficient Carbonated Hydroxyapatite. Thermal Decomposition. Journal of Solid State Chemistry 2001, 160, 340-349.

25. Kreinbrink, A. T.; Sazavsky, C. D.; Pyrz, J. W.; Nelson, D. G. A.; Honkonen, R. S., Fast-Magic-Angle-Spinning 19F NMR of Inorganic Fluorides and Fluoridated Apatitic Surfaces. Journal of Magnetic Resonance 1990, 88, 267-276.

26. Bielecki, A.; Kolbert, A. C.; De Groot, H.; Griffin, R. G.; Levitt, M. H., Frequencyswitched Lee-Goldburg sequences in solids. Advances in Magnetic and Optical Resonance 1990, $14,111-150$.

27. Fung, B. M.; Khitrin, A. K.; Ermolaev, K., An improved broadband decoupling sequence for liquid crystals and solids. Journal of Magnetic Resonance 2000, 142, 97-101.

28. Bodenhausen, G.; Vold, R. L.; Vold, R. R., Multiple quantum spin-echo spectroscopy. Journal of Magnetic Resonance 1980, 37, 93-106. 
29. Fu, R.; Hernandez-Maldonado, A. J., Boosting sensitivity and suppressing artifacts via multi-aquisition in direct polarization NMR experiments with small flip-angle pulses. Journal of Magnetic Resonance 2018, 293, 34-40.

30. Osman, M. B.; Diallo-Garcia, S.; Herledan, V.; Brouri, D.; Yoshioka, T.; Kubo, J.; Millot, Y.; Costentin, G., Discrimination of Surface and Bulk Structure of Crystalline Hydroxyapatite Nanoparticles by NMR. Journal of Physical Chemistry C 2015, 119 (40), 230082320.

31. Yesinowski, J. P.; Eckert, H., Hydrogen Environments in Calcium Phosphates: 1H MAS NMR at High Spinning Speeds. Journal of the American Chemical Society 1987, 109 (21), 62746282.

32. Wang, Y.; Von Euw, S.; Fernandes, F. M.; Cassaignon, S.; Selmane, M.; Laurent, G.; Pehau-Arnaudet, G.; Coelho, C.; Bonhomme-Coury, L.; Giraud-Guille, M.-M.; Babonneau, F.; Azais, T.; Nassif, N., Water-mediated structuring of bone apatite. Nature Materials 2013, 12, 1144-1153.

33. Jaeger, C.; Welzel, T.; Meyer-Zaika, W.; Epple, M., A solid-state NMR investigation of the structure of nanocrystalline hydroxyapatite. Magnetic Resonance in Chemistry 2006, 44, 573580.

34. Holzgrabe, U., Quantitative NMR Spectroscopy in pharmaceutical applications. Progress in Nuclear Magnetic Resonance Spectroscopy 2010, 57, 229-240. 
35. Posner, A. S.; Betts, F.; Blumenthal, N. C., Formation and Structure of Synthetic and Bone Hydroxyapatites. Progress in Crystal Growth and Characterization of Materials 1980, 3 , 49-64.

36. Elliott, J. C., Structure and Chemistry of the Apatites and Other Calcium Orthophosphates. Elsevier Science B.V.: Amsterdam, The Netherlands, 1994; Vol. 18.

37. Lotsari, A.; Rajasekharan, A. K.; Halvarsson, M.; Andersson, M., Transformation of amorphous calcium phosphate to bone-like apatite. Nature Communications 2018, 9 (1), 4170.

38. Posner, A. S.; Betts, F., Synthetic Amorphous Calcium Phosphate and Its Relation to Bone Mineral Structure. Accounts of Chemical Research 1975, 8 (8), 273-281.

39. Mkhonto, D.; de Leeuw, N. H., A computer modelling study of the effect of water on the surface structure and morphology of fluorapatite: introducing a Ca10(PO4)6F2 potential model. Journal of Materials Chemistry 2002, 12, 2633-2642.

40. Zeglinski, J.; Nolan, M.; Thompson, D.; Tofail, S. A. M., Reassigning the most stable surface of hydroxyapatite to the water resistant hydroxyl terminated (010) surface. Surface Science 2014, 623, 55-63.

41. Chiatti, F.; Piane, D. M.; Ugliengo, P.; Corno, M., Water at hydroxyapatite surfaces: the effect of coverage and surface termination as investigated by all-electron B3LYP-D simulations. Theoretical Chemistry Accounts 2016, 135 (54). 